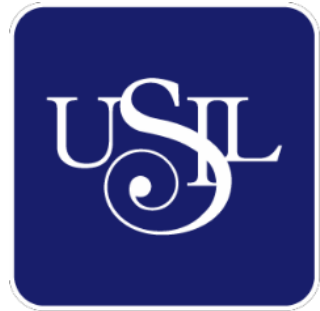

UNIVERSIDAD

SAN IGNACIO

DE LOYOLA

FACULTAD DE HUMANIDADES

Carrera de Arte y Diseño Empresarial

\title{
DISEÑO DE CAMPAÑA SOBRE LA SEGURIDAD EN EL TURISMO RECEPTIVO PARA REDES SOCIALES PARA CONTRIBUIR A AUMENTAR EL FLUJO DE TURISTAS RECEPTIVOS EXTRANJEROS DE 50 A 60 AÑOS EN EL CONTEXTO COVID-19
}

Tesis para optar el Título Profesional de Licenciado en Arte y Diseño Empresarial

\section{KATIA LUISA RAMOS DÍAZ}

\section{Asesor:}

Rafael Vivanco Alvarez

Lima - Perú

2020 
Dedicatoria

Este arduo proyecto, está dedicado a mi familia, compañeros, amigos y su servidora que desarrollamos la tesis en plena crisis sanitaria, económica, social y política. Hay que tener fuerza para no haber abandonado la tesis en un contexto tan podrido como el 2020. 
Agradecimientos

Agradezco a mis profesores, familia y amigos especialmente aquellos que han estado a mi lado. Y a todos los compatriotas que protestaron para sacar al nido de corruptos que teníamos en el congreso. 


\section{Resumen}

El proyecto abarca la investigación del turismo en el Perú en el contexto COVID - 19 durante el año 2020 y su pronóstico para el 2021, con la finalidad de saber cuáles son sus principales problemas y consecuencias. Es importante conocer más sobre el tema ya que ocupa el tercer sector más importante del país, representando el 12\% del PBI según el Ministerio de Economía (MEF, 2015). Estudios hechos por la Organización Mundial del Turismo (2019), aseguraban un crecimiento mucho mayor para el 2022. Expertos del sector como Guerra (2020) coincide en que el turismo peruano pudo crecer mucho más en los próximos 3 años, pero la crisis que deja la pandemia, le da a concluir que recién para el 2022 el turismo vuelva a recuperarse en comparación al 2019. Zubieta (2020), afirma que esta es la peor crisis que ha vivido el sector turismo en toda la historia. Se debe a que esta crisis dejó a más 2.7 millones de peruanos sin trabajo. Noticias RPP (2020), publicó que el 30\% de las empresas tuvieron que cambiar de rubro y las demás se declararon en quiebra. Además, reportes hechos por el Bloom consulting (2020), afirma que el perfil del turista ha cambiado, ya que el 64\% de los turistas afirmaron sentirse inseguros de viajar y otro $46 \%$ sentiría más confianza de viajar a países con buena infraestructura de salud y ofrezcan ofertas y paquetes turísticos flexibles.

\section{Palabras clave:}

COVID - 19, turismo, diseño gráfico, Perú 


\begin{abstract}
The project covers tourism research in Peru in the context of COVID - 19 during 2020 and its forecast for 2021, in order to know what its main problems and consequences are. It is important to know more about this issue since it occupies the third most important sector in the country, representing $12 \%$ of GDP according to the Ministry of Economy (MININTER, 2015). Studies carried out by the World Tourism Organization (2019), assured a much higher growth by 2022. Industry experts such as Diana Guerra (2020) agree that Peruvian tourism could grow much more in the next 3 years, but the crisis that leaves the pandemic, gives him to conclude that tourism will recover again in 2022 compared to 2019. Sandra Zubieta (2020), affirms that this is the worst crisis that the tourism sector has experienced in all history. This is because this crisis left more than 2.7 million Peruvians without work, according to the INEI. RPP News (2020), published that $30 \%$ of the companies had to change their category and the others declared bankruptcy. In addition, reports made by Bloom consulting (2020), affirm that the tourist profile has changed, since $64 \%$ of tourists said they felt unsafe to travel and another $46 \%$ would feel more confident traveling to countries with good health infrastructure and offer flexible tour packages and deals.
\end{abstract}

\title{
Key Words
}

COVID - 19, tourism, graphic design, Peru

\section{Índice}


Resumen

Abstract PAGINAS??????

Capítulo I

Introducción.

Descripción del problema encontrado.

Problema principal.

Problemas secundarios.

Justificación de la Investigación.

Objetivo principal.

Objetivos secundarios.

Pregunta de Investigación.

Hipótesis.

Capítulo II

Análisis de los actores.

Análisis del campo.

Metodología del problema

Metodología del proyecto.

Capítulo III

Turismo

Turismo en el Perú

Tipos de Turistas 
COVID - 19

Principales consecuencias del COVID - 19 en el Perú y el Mundo.

Turismo en el contexto COVID - 19

Nuevo perfil de turista receptivo e interno en el contexto COVID - 19

Medidas de prevención ante el COVID - 19 para el sector turismo.

Mypes en el sector del turismo del Perú

Importancia de la Mypes del sector turismo en el Perú

Empleabilidad en el sector turístico

Empleabilidad en el sector turístico COVID - 19

Tasa de empleo del sector turístico en el 2015 y el 2020

Diseño de producción de contenidos

Contenidos digitales para redes sociales

Videos

Fotografías

Ilustraciones

Infografías

Estrategias de Comunicación de contenido para el turismo en COVID - 19

Estado Del Arte.

Capítulo IV

Público Objetivo.

Concepto.

Moodboard. 
Paletas de color.

Tipografías.

Proyecto de Diseño.

Relación entre Problema, Público Objetivo y Proyecto.

Marca del proyecto.

Resultado.

Diseño de Comunicación.

Piezas empleadas.

Reflexiones

Conclusiones

Referencias Bibliográficas

Anexos 


\section{Capítulo I}

\section{Introducción.}

Con la aparición del nuevo coronavirus, el mundo se ha visto paralizado sin excepciones, según la Organización Mundial de Salud (2020), esta pandemia se puede considerar una de las peores crisis sanitarias en toda la historia de la tierra. Y para la Organización Mundial del Turismo (OMT, 2020), esta es la peor crisis que ha atravesado el sector turismo, ya que a través de la línea del tiempo no se había enfrentado un reto tan grande y global. La directora de la carrera de Administración Hotelera, Turismo, Gastronomía y Arte culinario, Sandra Zubieta (2020) y la ex directora Diana Guerra (2020), concuerda con la OMT, en que es la peor crisis que han atravesado, ya que en otras situaciones el turismo se paralizaba de forma local, pero en este contexto la crisis sanitaria fue global y por ende sus consecuencias tuvieron un efecto masivo y prolongado. Por esta razón, en este proyecto, investigaremos el pronóstico de reducción del flujo de turistas de 50 a 60 años para el 2021 a raíz del número de contagios y muertes por COVID - 19 en el Perú, todo eso comprobado por las estadísticas y reportes brindadas por Promperú y TurismoIn en sus páginas web. Carlos Canales (2020), presidente de la cámara de cámara nacional del turismo en Perú, señala que el turismo se verá gravemente afectado por las medidas de prevención contra el COVID - 19 y por las bajas cifras de turismo receptivo durante el 2020, lo que genera una situación de insolvencia para varias empresas del sector turismo y por lo tanto dejará a más de 800 mil empleos en riesgo de forma directa e indirecta.

\section{Descripción del Problema Encontrado.}

Varios medios de comunicación como la agencia de noticias Andina, publicó el 17 de agosto que el viceministro del Salud Pública del Perú informó que la vacuna para 
el COVID - 19 llegará al Perú alrededor del Segundo trimestre del 2021.

Hasta que la situación no tenga una solución concisa, el turismo es un sector bastante incierto, ya que depende de la estabilidad de muchos factores, por ejemplo, en el contexto COVID - 19, en agosto del 2020, Asia y España mostraban preocupación por un segundo rebrote, lo cual pone al turismo interior y receptivo en una posición inestable. Si bien hay mucho que aprender e investigar sobre el SARS - COV 19, el centro chino para el control y la prevención varía en función a la edad, es decir personas mayores de 50 años; gente con problemas pulmonares, con diabetes o sobrepeso; mujeres embarazadas; niños y bebes. Reportes del PROMPERU (2020), revelan que la pandemia ha ocasionado un cambio en el comportamiento del turista, especialmente en el turista mayor, ya que se siente más desconfianza al viajar, muchos de ellos esperan a finales del 2021 donde la crisis sanitaria y económica sea estable. Lo que se verá reflejado en el flujo de turistas receptivos de este y el próximo año. Por otra parte, según noticias RPP, más de 5 mil millones de peruanos se han quedado sin trabajo, de los cuales 800 mil son del sector turismo. En una encuesta realizada por Katia Ramos (2020) a 54 profesionales del sector turismo, el $70 \%$ de ellos se encontraba desempleado, 27 de ellos se encontraba estudiando o haciendo un diplomado, enseñando inglés o francés, y 13 de los encuestados estaba emprendiendo. Esta alta tasa desempleo se debe a que las pequeñas y medianas empresas han quebrado; otras que están paralizadas y se han visto en la obligación de reducir costos, y a falta de demanda se despidió gente para que el negocio pudiera subsistir.

\section{Problema principal.}

Pronóstico de Reducción del Flujo de Turistas de 50 a 60 años para el 2021 a raíz del elevado número de contagios y muertes por el COVID - 19 en el Perú. 


\section{Problemas secundarios.}

Alta tasa de desempleo del sector turismo como consecuencia del Pronóstico de Reducción del Flujo de Turistas de 50 a 60 años para el 2021 a raíz del elevado número de contagios y muertes por el COVID - 19 en el Perú.

Quiebra de pymes del sector turismo debido al Pronóstico de Reducción del Flujo de Turistas de 50 a 60 años a raíz del elevado número de contagios y muertes por el COVID- 19 en el Perú.

\section{Justificación de la investigación}

Es alarmante el contexto y las consecuencias que esta pandemia, en el diario Gestión (2020), se confirma la despreocupación de las personas que amontonaban los mercados, no respetaban el aislamiento ni los lineamientos de prevención. No obstante, problemas como el desempleo generó que muchas personas salieran a las calles a trabajar de manera informal. Estos factores ocasionaron que, para agosto del 2020, Perú fuera el país con mayor número de contagios y muertes por COVID- 19. El doctor Gotuzzo (2020), profesor y exdirector de la Universidad Cayetano Heredia de Lima, señala que los factores que nos pusieron en esa posición alarmante fue la baja inversión en salud, la escasez de camas hospitalarias, el personal mal pagado y un solo laboratorio para hacer pruebas moleculares. Eso ocasiona mucha desconfianza en potenciales turistas de todo el mundo. Las estadísticas del Bloom Consulting (2020) afirman que el turista busca sentirse seguro y a salvo en un lugar donde se tomen las medidas adecuadas. De ese modo, eventos tan importantes como el bicentenario del Perú, se verá afectado, especialmente en el turismo receptivo. Rafael Parra (2020), gerente del hotel boutique "Casa República”, confirma que el turismo receptivo representa la mayor parte de ingresos en comparación al turismo interno, como también señala que el 2021 va a ser un año muy bajo para el sector, y 
quienes van a liderar los viajes son los millenialls, aunque no tienen mucho presupuesto en comparación de la generación x y baby Boomer. El turismo representó el 12\% del PBI anual del Perú, los ingresos que generaba este sector son fundamentales para disminuir el desempleo y mejorar la economía del Perú.

\section{Objetivo principal.}

Investigar el Pronóstico de Reducción del Flujo de Turistas de 50 a 60 años para el 2021 a raíz del elevado número de contagios y muertes por el COVID - 19 en el Perú.

\section{Objetivos secundarios.}

Señalar la alta tasa de desempleo del sector turístico como consecuencia del Pronóstico de Reducción del Flujo de Turistas extranjeros de 50 a 60 años para el 2021 a raíz del elevado número de contagios y muertes por el COVID - 19 en el Perú.

Justificar la Quiebra de pymes del sector turístico debido al Pronóstico de Reducción del Flujo de Turistas de 50 a 60 años a raíz del elevado número de contagios y muertes por el COVID- 19 en el Perú.

\section{Pregunta de Investigación.}

¿En qué medida el diseño de contenidos para redes sociales de turismo peruano puede contribuir a aumentar el flujo de turistas receptivos de 50 a 60 años en el Perú - Contexto COVID - 19?

\section{Hipótesis.}

El diseño de contenidos para redes sociales de turismo peruano puede contribuir a aumentar el flujo de turistas receptivos de 50 a 60 años en el Perú - Contexto COVID - 19. 


\section{Capítulo II}

\section{Análisis de los Actores.}

\section{Turistas de 50 a 60 años.}

Los reportes estadísticos del flujo de turistas hechos por el Bloom Consulting (2020), este segmento siente desconfianza de viajar a lugares donde hay un alto número de contagios y muertes. Este target es más vulnerable a la enfermedad, por ello el miedo es más grande que el deseo de viajar en general.

\section{Propietarios de hoteles y hostales.}

Hasta el momento, ya muchos hoteles han cerrado por la cuarentena. No obstante, para aquellos están paralizados, esperan que este sector se vea reactivado, cuando haya una solución concisa para el COVID - 19. Más adelante, cuando este sector sea reactivado, dentro de los lineamientos exigidos por Mincetur (2020) está el bajar el aforo a un 50\%, como medidas de prevención al COVID - 19, lo que implica brindar ofertas y promociones más flexibles.

\section{Promperú.}

Es un organismo técnico especializado con personería jurídica de derecho público interno que goza de autonomía funcional, técnica, económica, financiera, presupuestal y administrativa. Se encuentra adscrita al Mincetur y constituye un pliego presupuestal. Es una comisión competente para formular, aprobar, ejecutar y evaluar las estrategias y planes de promoción de bienes y servicios de exportación y turismo interno y receptivo.

\section{Mincetur.}

Este ministerio se encarga de definir, dirigir, ejecutar, coordinar y supervisar la política del comercio exterior y turismo en el país como órgano rector del sector. Y cómo objetivo estratégico: la promoción de la internacionalización de la empresa y la 
diversificación, competitividad y sostenibilidad de la oferta exportable. En materia de turismo, promueve el desarrollo de la actividad turística como un medio para contribuir al crecimiento económico y al desarrollo social del País, contribuye al fortalecimiento de la identidad, el respeto a la diversidad cultural, fomentando la conciencia turística.

\section{Microempresas del sector turístico.}

Las pequeñas y medianas empresas tienen un gran reto en este contexto, cuando todo vuelva a reactivarse. La principal razón de ello, es porque los ingresos no serán lo suficientes ya que el flujo de clientes será menor en comparación a otros años. Aparte las medidas tomadas tras el COVID - 19, las cuales serán algo difícil de llevar más no imposible. Por otro lado, las empresas que son nuevas no se han ganado la confianza de los clientes, por lo que promover y publicitar estos lugares va a ser más difícil, porque hay que comprobar que realmente cumplen las medidas de prevención que el Mincetur y Promperú exigen que tengan. Para esto, Las pequeñas y medianas empresas de este sector tendrán que empiezar a usar publicidad para ganarse la confianza de los clientes y fomentar el flujo de turismo interno y externo.

\section{Líneas Aéreas.}

Líneas aéreas como LATAM y AVIANCA, se declararon en bancarrota, ya que en los primeros meses de cuarentena todo se paralizó con tal de detener el contagio del COVID - 19. Para el 31 de julio, pronosticaron que para finales del 2020 o inicios del 2021 podrían reanudarse los vuelos internacionales. Hay casos en los que sí se puede hacer viajes de urgencia, pero el gobierno tiene que autorizarlo y para ello tienen que pasar por el departamento legal de los aeropuertos, lo cual hace más difícil que se pueda hacer un viaje en general, reactivar este sector es muy difícil pero importante para que el turismo también se reactive. También hay que tener en cuenta, al ser el 
país con mayor número de contagios, los gobiernos de otros países toman medidas bastante rigurosas para dejar pasar a cualquier extranjero y sólo si es un viaje de emergencia. En este aspecto, quien mayor responsabilidad tiene en este sector es el ministerio de transporte, así que el turismo afecta a más de un sector.

\section{Empleados de Centros Turísticos.}

Desde ya hay muchos desempleados en el sector turismo por el coronavirus. Y tras hallar una solución a este problema sanitario, va a haber una gran competencia para poder trabajar en este rubro, cómo también, muchos se van aventurar a emprender, lo cual es muy difícil. Durante la crisis, varios han cambiado de sector, y están vendiendo cosas en línea, ayudan al negocio familiar sin salir de sus casas, para poder cuidar su salud y la de sus familiares, amigos y sociedad. Obviamente los ingresos no son iguales, ya que se busca es subsistir más que generar ingresos.

\section{Profesionales del sector turístico.}

Jefe de restaurantes, chef de cocinas, guías turísticos, y los propietarios de estos negocios, también se verán afectados por el desempleo. Muchos han optado por seguir capacitándose, para poder ser un buen candidato para trabajar cuando el sector vuelva a reactivarse. Pero qué tan rentable será para ellos, ya que aún no es seguro si los sueldos se mantendrán o disminuirán.

\section{Análisis del Campo}

Agencias web.

a) LAN, b) Despegar.com, c) Airbnb, d) Avianca, e) Expedia, f) Booking.es

\section{Redes Sociales.}

Facebook, Instagram y YouTube.

\section{Blogs de viajes.}

a) Misias pero viajeras, b) Viaja y prueba, c) Lápiz Nómada, d) Marcando el polo. 
e) Aprendizaje Viajero, f) Viajando por ahí, g) Viajera Difgital

\section{Metodología del Problema.}

Se desarrolló un plan de trabajo que servirá para poder ordenar la investigación, los métodos fueron: Encuestas y entrevistas.

\section{Encuestas.}

La primera encuesta a profesionales del sector turístico, se realizó una encuesta en línea a 54 personas del rubro turístico, de distintos puestos dentro de una agencia para saber qué tan afectados están los empleados de ese rubro.

La Segunda encuesta a peruanos de 50 a 60 años, con un alcance de 55 participantes para saber cuál es su interés en hacer turismo interno o extranjero para el próximo año. Saber el interés de este target en viajar, si su interés es muy bajo indagar en las razones de su desconfianza y cuando volverían a viajar. Cuáles son las principales disyuntivas que encuentran entre viajar o seguir quedándose en casa.

\section{Entrevistas.}

El primer grupo entrevistado fueron turistas externos de 50 a 60 años, de países como Francia, España y Canadá, para así conocer las razones por las cuales quieren viajar al Perú y en qué fechas, caso contrario preguntar las principales razones por las cuales no desean viajar entre el 2020 y 2021.

El segundo grupo a entrevistar fueron propietarios o gerentes de pequeñas y medianas empresas del sector turístico, por ejemplo: Operador turístico, Hostal y Catering. Con la finalidad de averiguar qué medidas piensa tomar, cuando el turismo comience a funcionar de manera regular y cuáles son las principales amenazas en este sector.

El tercer grupo entrevistado fueron las expertas en el sector turístico, ejemplo: directora de la Facultad de Administración Hotelera, Turismo, Gastronomía y Arte 
culinario; Exdirectora de la Facultad de Administración Hotelera, Turismo, Gastronomía y Arte culinario; Especialista en estadísticas de demanda turística de TURISMO IN.

\section{Metodología del Proyecto}

Los turistas receptivos de 50 a 60 años significan el 25\% del flujo turístico que llega al Perú, sus principales motivos de viaje son familia, ocio, negocios y viajes de pareja según TurismoIn (2020). De la misma fuente se sabe que en su mayoría los que vienen de Oceanía, África y Europa son quienes más ingresos le generan a las pymes del sector turístico según las estadísticas de Promperú, ya que tienen un estilo de vida un poco más elevado. No obstante, con el contexto COVID - 19, muchos de ellos al ser población vulnerable, se preocupan mucho por cuidar su salud y tienen miedo a viajar por largas horas y contraer el virus. Prefieren hacer viajes cortos (turismo interno), que no requiere mucho contacto con la gente. Por tal razón, se crea el concepto "Seguridad para viajar con Libertad", con el objetivo de diseñar contenido para redes sociales (Facebook, Instagram y YouTube) de turismo peruano, para generar confianza en este segmento receptivo y contribuir al aumento de flujo de turistas receptivos. 


\section{Capítulo III}

\section{Turismo}

El concepto turismo tiene muchas definiciones dentro del proceso investigativo de las actividades turísticas, Jiménez (2013). Por esa razón, en está ocasión se comienza por la definición de la RAE, el cual dice que la palabra Turismo viene del inglés Tourism y se define como la actividad y hecho de viajar por placer. Desde la vista de Jiménez (2013), nace de las palabras latinas: “tour y torn”, las cuales significan “tornar”, que significa movimiento y retorno. Esa definición se viene construyendo desde la revolución industrial, ya que fue en esos tiempos que comenzó a separarse el trabajo y el ocio. Thomas Cook fue la primera agencia de viajes a través de la historia, Silvia Pato (2020), narra en el blog de descubrir.com, quien dio inicio a estas actividades fue Thomas Cook, el padre del turismo, quien usó las nuevas herramientas de la revolución industrial para llevar y traer a un grupo de personas para que reciban una charla para dejar el alcohol. Para ello, tuvo que planear los puntos de descanso, coordinar alojamientos, comidas en buenos restaurantes y los tickets del tren. A través de la historia, las nuevas tecnologías han ido modernizando la manera de viajar de las personas, al igual que los motivos por los cuales viajan, por ejemplo, Promperú separa el tipo de turismo en el Perú de la siguiente manera: ocio, académico, negocios, aventura, naturaleza, cultural, artesanal, vivencial y más.

\section{Turismo en el Perú.}

El turismo es la tercera industria más importante del Perú, después de la pesca y la minería. Promperú asegura en sus estadísticas que el turismo ha tenido una tasa de crecimiento del $25 \%$ en estos últimos cinco años, y eso se debe a que el índice de satisfacción de los turistas después de visitar el Perú es de 94\%. Logrando un impacto del 12\% del PBI del Perú, según CANATUR. Lo cual indica que es un 
sector de gran crecimiento, el cual emplea al 11\% de la población (848.000 directos y 340.000 indirectos) en su mayoría en hostelería y transporte. En los reportes web mostrados por TurismoIn, el análisis refleja que sólo por los Juegos Panamericanos y Parapanamericanos del 2019, el flujo de visitantes llegó a 3,1 millones en el trayecto de este gran evento. Los países de origen fueron: Chile, EEUU, Ecuador, Colombia y Argentina. Por otro lado, datos de Wikipedia afirman que, en el 2010, más de 2 millones de turistas internacionales visitaron Perú, provenientes de: Chile, EEUU, Ecuador, Argentina, Colombia, España, etc. Cabe resaltar que sus principales lugares de visita fueron: Cusco, Lima, Tumbes, Tacna, Arequipa y Puno.

\section{Tipos de Turistas.}

Turista receptivo. El turista receptivo se conoce como aquel que viene de afuera del país. Desde la perspectiva de Kotler y Keller (2016) en los reportes de PROMPERÚ, se separa los tipos de turistas por generaciones para definir el perfil de los turistas extranjeros que llegaron al Perú en el 2018. Los cuales están divididos en:

Tabla 1

Perfil del Turista Extranjero 2018

\begin{tabular}{|l|l|l|l|l|l|l|}
\hline $\begin{array}{l}\text { Tipo de } \\
\text { Turista }\end{array}$ & Año & $\%$ & $\begin{array}{l}\mathrm{N}^{\circ} \mathrm{de} \\
\text { vuelos }\end{array}$ & $\begin{array}{l}\text { Gasto por } \\
\text { persona }\end{array}$ & Noches & Hotel / Hostal \\
\hline Centennial & $1995-2016$ & $18 \%$ & 478534 & $\begin{array}{l}955 \\
\text { dólares }\end{array}$ & 13 noches & $\begin{array}{l}1 \text { a } 2 \text { estrellas } \\
\text { Hotel /Hostal }\end{array}$ \\
\hline Millenial & $1979-1994$ & $47 \%$ & 1295272 & $\begin{array}{l}971 \\
\text { dólares }\end{array}$ & 11 noches & $\begin{array}{l}\text { Hotel / Hostal } \\
\text { Generación X }\end{array}$ \\
\hline $1965-1978$ & $18 \%$ & 504294 & $\begin{array}{l}964 \\
\text { dólares }\end{array}$ & 8 noches & $\begin{array}{l}\text { Ho 2 estrellas } \\
\text { Hotel / Hostal }\end{array}$ \\
\hline $\begin{array}{l}\text { Baby Boomer } \\
1946-1964\end{array}$ & $16 \%$ & 427486 & $\begin{array}{l}1177 \\
\text { dólares }\end{array}$ & 8 noches & $\begin{array}{l}3 \text { estrellas } \\
\text { Hotel / Hostal }\end{array}$ \\
\hline $\begin{array}{l}\text { Generación } \\
\text { Silenciosa }\end{array}$ & $1925-1945$ & $1 \%$ & 23147 & $\begin{array}{l}2652 \\
\text { dólares }\end{array}$ & 8 noches & 4 a 5 Hotel \\
\hline
\end{tabular}

Descripción del tipo turista por año, porcentaje, vuelos, gasto, noches y alojamiento, Promperú (2019) 
En la tabla 1, podemos observar que los millenialls son quienes más viajan al Perú, por otro lado, son los Baby Boomer y la generación silenciosa quienes más gastan. No obstante, las Generación X junto a los Centennial son parte del segundo grupo más grande que viene al Perú.

Turista interno. Según las estadísticas de Mincetur (2019), los viajes en el 2019 representaron el 92\% del total viajes en el Perú, es decir 53 millones de viajes se hicieron por turismo en el Perú y 48,6 millones fueron viajes nacionales. La mayoría de los traslados son desde lima, lo que en el 2019 representó el 86\% del movimiento económico. Estas son las cifras notables de las estadísticas del perfil del vacacionista por grupo de viaje, según TurismoIn (2018).

\section{COVID - 19}

La organización mundial de salud (2020) señala que:

"Los coronavirus son una extensa familia de virus que pueden causar enfermedades tanto en animales como en humanos. En los humanos, se sabe que varios coronavirus causan infecciones respiratorias que pueden ir desde el resfriado común hasta enfermedades más graves como el síndrome respiratorio de Oriente Medio (MERS) y el síndrome respiratorio agudo severo (SRAS). El coronavirus que se ha descubierto más recientemente causa la enfermedad por coronavirus COVID-19”. (Sitio web mundial)

Como podemos observar en este párrafo, se entiende que el coronavirus es un virus que siempre ha existido, no obstante, hay muchos tipos de coronavirus y el COVID 19 es el último que ha sido descubierto. La OMT (2020), explica que "La COVID19 es la enfermedad infecciosa causada por el coronavirus" (Website mundial), este virus brotó en Wuhan (China) en diciembre del 2019. Lo que afectó a muchos países 
en todo el mundo causando muchos contagios y muertes. Estadísticas de la OMT (2020), muestras que, hasta octubre del 2020, ha habido 39.8 millones de casos en todo el mundo, del cual 27.3 millones se recuperaron y 1.11 millones murieron.

\section{Principales consecuencias del COVID - 19 en Latinoamérica y el Perú.}

En Latinoamérica y el Caribe. En breves palabras la Naciones Unidas (2020), resalta que "Antes de la pandemia, el modelo de desarrollo de la región ya enfrentaba graves limitaciones estructurales: elevados niveles de desigualdad, limitaciones de las balanzas de pagos y exportaciones concentradas en sectores de baja tecnología" (pág. 1). En el mismo informe, las Naciones Unidas (2020) también anuncia que "La respuesta al COVID-19 debería acercarnos a la visión de la Agenda 2030 para el Desarrollo Sostenible en cuatro dimensiones clave sustentadas firmemente en los derechos humanos: Dimensión Social, Económica, ambiental y política” (pág.3). En este enunciado, se entiende que está pandemia destacó considerablemente los problemas sociales que Latinoamérica y el caribe tenían desde hace mucho tiempo. Para las Naciones Unidas (2020). Por estas razones, La OMS afirma que "El COVID - 19 está provocando la peor crisis sanitaria, económica, social y humanitaria de la región en un siglo". El en siguiente párrafo profundizaremos brevemente las razones según el informe hecho por la Naciones Unidas (2020):

Impactos Sanitarios. Varios países de América Latina y el caribe presentan algunas de las cifras más altas de casis en términos absolutos y per cápita de todo el mundo. Ya que cuenta con sistemas de salud fragmentados, desigualdades y no están preparados para enfrentar una crisis sanitaria y humana de esta magnitud (pág.8). Impactos económicos. La CEPAL estima que el PIB de américa Latina y el caribe podrían disminuir un $9,1 \%$ en 2020 . Sectores como turismo, transporte, servicio 
empresariales y sociales. Según el informe de las naciones unidas, las mujeres se verán muy afectadas, ya que estos rubros emplean al 78\% de las mujeres en el mercado laboral (pág. $9-10)$.

Repercusiones sociales y humanitarias. Se estima que la tasa de pobreza a amentara 7 puntos porcentuales en el 2020, hasta alcanzar el 37,2\% lo que representa 28 millones de personas que tendrán graves problemas económicos, por lo que los niveles de desigualdad se verán notablemente reflejada. (pág. 13)

En el Perú. Para señalar este aspecto, se va separar el impacto en tres partes, como en el informe de las Naciones Unidas (2020): Impacto Sanitario, Impacto Económico y Repercusiones sociales y humanitarias.

Impacto económico. Director de la carrea de Economía de la Universidad de Lima, Pedro Grados Smith (2020), reflexiona que en lo va del año habría una caída del 5\% del PBI, en el peor de los casos sería de un $15 \%$ a $20 \%$. Eso se debe a que lo sectores duramente afectados son: El sector Turismo y Transporte, se han visto duramente afectados. Muy a diferencia de los supermercados y las nuevas tecnologías, los cuales han aumentado su demanda en este contexto. Pedro Grados Smith (2020), afirma que:

“La reactivación será paulatina. Según los funcionarios del Estado, la economía está funcionando en un $44 \%$ de su capacidad. La primera fase de apertura va a aumentar esta cifra hasta $70 \%$ u $80 \%$. En las etapas tercera y cuarta se llegará a $95 \%$ y luego a $100 \%$. Algunos asumen que eso va a ocurrir este año, otros consideran que podría tardar 2 años hasta que recuperemos nuestro PBI per cápita” (Web Page, U. Lima) 
Está entrevista ayuda a ver una perspectiva del Impacto Económico de tendrá está pandemia, desde la perspectiva de Pedro Grados.

Impacto Sanitario. Estadísticas de la Organización mundial de la salud (2020), informan que, para octubre del 2020, Perú tiene 862 millón de casos, de los cuales 774 millón de ellos se recuperaron y 33, 648 murieron. A eso se le suma, que en noticieros como RPP (2020), informaron que el sistema de Salud colapsó, por la falta de camas, medicinas y equipos de pruebas moleculares.

Repercusiones sociales y humanitarias. En Perú, las repercusiones fueron el desempleo, la pobreza, la desigualdad, el número de casos de mujeres maltratadas se volvió más alarmante, casos de violaciones intrafamiliares salieron al ojo público.

\section{Turismo en el contexto COVID - 19}

La pandemia del COVID - 19 trajo terribles consecuencias, sanitarias, económicas y sociales en todo el Mundo, unos países más que en otros. Pero uno de los sectores más afectados fue el sector turismo, ya que según los datos del World Tourism Organization (UNWTO, 2020): "Los viajes internacionales de turismo han disminuido un $22 \%$, con escenarios de entre $-60 \%$ y - $-80 \%$ en comparación con las cifras del 2019”. En la misma nota, la UNWTO (2020) afirma que el turismo representa un sector de suma relevancia ya que representa un fuerte soporte para la economía y el trabajo, a un nivel nacional como internacional. Por esta razón, UNTWTO (2020), anuncia que la pandemia COVID - 19, es la peor crisis que ha tenido el turismo en toda la historia. Por esa razón, grandes entidades como OMT, UNTWTO, MINCETUR, CANATUR y PROMPERU, se han dedicado a hacer reportes, investigaciones y análisis acerca del turismo en el contexto COVID - 19, con la finalidad de hallar una manera de afrontar el contexto de la manera más efectiva para los empresarios, profesionales y turistas. Hasta octubre del 2020, el 
turismo se ha reactivado en Europa, Asia y algunos países de Latinoamérica dentro de ellos México y Perú.

\section{Turismo Peruano en el contexto COVID - 19.}

El 1 de octubre del 2020, el diario Gestión (2020) informó que los vuelos internacionales y nacionales ya estaban permitidos, las principales razones fueron que los lineamientos fueron ejecutados eficazmente y el número de contagios y muertes disminuyó. Por lo tanto, los hospitales ya tenían menos pacientes en urgencias, además que la calidad del servicio de los hospitales mejoró tras la crisis sanitaria. Oficialmente Benavente (2020) informó que el 15 de octubre se reiniciaría el Turismo interno en el Perú, en el caso de Machu Pichu reabrió sus puertas el 1 de noviembre 2020. Por lo que básicamente, para inicios de noviembre, el estado decidió que la entrada a Machupichu sea gratuita para todos los peruanos con el objetivo de fomentar el turismo interno y así reactivar la economía en ese sector. Por otra parte, el portal informativo de CANATUR (2020), anunció que el 13 de octubre el Perú recibió el Sello "Safe Travels" del Consejo Mundial de Viajes y Turismo, el primer sello de seguridad e higiene del mundo para el turismo ante la COVID - 19. Este sello fue creado con el Objetivo de contribuir a la reapertura responsable y segura del turismo, cabe mencionar que la organización Mundial de Turismo respalda ese sello, por ente este sello representa seguridad y confianza. La ministra Barrios (2020) indica que:

"Esta tarea ha sido cumplida a cabalidad, lo que le permite a nuestro país contar con estándares de seguridad sanitaria en turismo de nivel mundial. El turismo es la actividad económica que ha sufrido el mayor golpe por la pandemia del coronavirus. Por ello, para su reactivación, queremos ofrecer a los visitantes la mejor experiencia de viaje posible, con destinos y servicios 
turísticos de calidad y cumpliendo estrictos protocolos de bioseguridad.

Tenemos el compromiso del sector público y privado. Vamos a volver, es el momento". (Portal web de Canatur)

Guevara (2020) destacó que el Perú es considerado un gran destino de viaje a nivel internacional, e indicó que el sello tiene como objetivo principal recuperar la confianza de los visitantes. Lo que concluye en que el Perú está tomando todas las medidas y lineamientos para poder reactivar el sector Turismo, por el momento lo hacen de forma gradual para evitar un rebrote. A Inicios de noviembre del 2020, Parque temáticos, Machu Pichu y restaurantes están abiertos para el público.

\section{Nuevo perfil de turista receptivo e interno en el contexto COVID - 19.}

Nuevo perfil del turista receptivo. A mediados de junio del 2020, el Bloom Consulting Y C2 - Analytics (2020) realizaron un reporte que señala el cambio de comportamiento del turista como un efecto de la pandemia, con la finalidad de que saber que esperar en un futuro cercano. Para ello el Bloom consulting y C2 Analytics (2020), realizaron una encuesta en la cual simularon 3 posibles escenarios, respondiendo a la siguiente pregunta “ ¿Viajaría por ocio nuevamente en los siguientes 12 meses?”:

Escenario 1. "El virus es controlado y se vuelve parte de nuestras vidas", en este primer escenario los resultados fueron los siguiente: $45 \%$ respondieron que no viajarían, y el otro 55\% respondieron que sí.

Escenario 2. "El virus está cerca de erradicarse, ya que hay un tratamiento", en este escenario las respuestas fueron más positivas, $65 \%$ respondió que si viajaría y el otro $35 \%$ no viajaría. 
Escenario 3. "El virus se ha erradicado por completo", por último, en el mejor escenario de todos, el $85 \%$ de ellos si viajaría, y un $15 \%$ no lo haría.

En el reporte del Bloom Consulting y D2 - Analytics (2020) nos explica las razones de porque la gente no quiere viajar en el contexto - COVID - 19:

"Less income will not be the main reason for less tourist, Although the reduction of disposable income is a major consequence of this crisis, it will not be the main reason behind tourists refusing to travel" (pág. 19-24)

El 64\% de los encuestados respondieron que la verdadera razón por la cual no viajarías en porque se sienten inseguros de viajar. Por lo que, Bloom Consulting (2020) afirma que "Fear transcends desire", por lo que viajar por placer no es una opción agradable en el escenario número 1.

La única manera en la cual viajarían sería si tuvieran las mismas ofertas, pero adaptadas a las nuevas necesidades y expectativas al contexto COVID -19 . Y se sentirían más seguros si al lugar al que viajan tuvieran un gobierno estable, con una buena infraestructura de salud y un sistema de prevención.

Nuevo perfil de turista interno del Perú. De acuerdo a Ipsos Perú (2019) el 56\% de los peruanos ya tenían la costumbre de viajar por ocio. No obstante, TurismoIn (2020) dice que "los viajes en la nueva normalidad vienen acompañados de un cambio en las percepciones y hábitos” (pág. 4 - 5), Esto se deben a que dentro del público que viajaría, considera la bioseguridad como un elemento clave para animarse a viajar, por ejemplo: El 74\% de ellos da suma importancia que los establecimientos tengan buenos protocolos de prevención de riesgos de contagio, el $50 \%$ opina que aforo debe reducirse, otro $48 \%$ quiere tener acceso a información de los servicios vía online y por último un $37 \%$ desea una buena relación calidad - 
precio con opciones de compra y reserva online. Cabe mencionar que el público al cual Promperú (2020), recomienda dirigirse son a los Millenial y centennial ya que son el público que tiene menos riesgo de contagio, más sensibilidad al contagio y más ganas de viajar; No obstante, Guerra (2020), está en desacuerdo con ello porque los centennial del Perú no disponen de la solvencia económica en comparación a un Millenial. Por otra parte, según PROMPERU (2020), las estrategias que ayudarían a ganarse la confianza del público que desea volver a viajar dentro de 3 a 6 meses son: ofrecer destinos, actividades y transporte privados; Límites de densidad; mostrar protocolos clases y segmentación horaria; Incluir testimonios, referencias y por último recuperar la confianza de los habitantes.

\section{Protocolos Sanitarios Sectoriales ante el COVID - 19 para el sector turismo}

El Mincetur (2020) publicó los protocolos Sanitarios sectoriales ante el COVID - 19, los cuales se dividen en Agencias de Viajes y Turismo, Hoteles Categorizados, Transporte, Albergues, guiado turístico, restaurantes, apart - hotel y hostales. Por lo que en esta ocasión se destacan los aspectos más resaltantes de: Agencias de Viajes, Hoteles Categorizados y Restaurantes.

\section{Protocolos Sanitario Sectorial ante el COVID - 19 para agencias de viaje y}

Turismo (2020). Las agencias de viaje y turismo deben:

“A) Verificar y/o efectuar la limpieza y desinfección antes y después de cada uso y guardarlo protegido. B) Vigilar el cumplimiento del programa de limpieza y desinfección del equipamiento de turismo de aventura de acuerdo a la modalidad. B) Verificar y/o ejecutar que se asigne de forma exclusiva el equipamiento de turismo de aventura por cada pasajero. C) Velar y/o asegurar que se mantenga la distancia físico al menos $1 \mathrm{~m}$ a la hora del uso del equipamiento.” (pág. 13 - 17) 
Se menciona que los protocolos son más extensos y exigentes, y que esta citación es para explicar brevemente una idea de los que contiene el protocolo sanitario.

\section{Protocolo Sanitario Sectorial Ante el COVID - 19 para hoteles categorizados}

(2020). Los hoteles categorizados deben:

“A) Acondicionar un área o punto de sanitizado (preferentemente al ingreso), con todos los accesorios necesarios, tales como: grifo de agua, jabón, desinfectante, papel toalla, tacho con tapa, pediluvio e instructivos de lavado de manos. B) Implementar desinfectantes de manos en puntos estratégicos del alojamiento en buenas condiciones de higiene y operatividad. C) Acondicionar un área para la recepción de productos e insumos, con todos los materiales y equipos necesarios, tales como: parihuelas, equipos de transporte, carretillas, etc.; de fácil limpieza y desinfección. D) Implementar vestidores exclusivos del personal con las respectivas duchas, bancas y facilidades para disponer la ropa de trabajo y de diario de manera que unas y otras no entren en contacto. Mantener en buen estado de operatividad, orden y limpieza los vestidores. E) Acondicionar un área de cuarentena para los productos que ingresen en observación por un posible riesgo de contagio durante el traslado o manipulación. F) Acondicionar lavaderos exclusivos para la limpieza y desinfección de las herramientas de limpieza u otros materiales. G) Contar con almacén exclusivo para insumos y materiales de limpieza.” (pág. $11-12$ )

Se menciona que los protocolos son más extensos y exigentes, y que esta citación es para explicar brevemente una idea de los que contiene el protocolo sanitario.

Protocolo Sanitario Sectorial Ante el COVID - 19 para restaurantes (2020). Los restaurantes deben: 
“A) La distancia entre los bordes de las mesas del salón cuando los comensales se dan la espalda debe ser de 1.5 metros, de no ser posible esto, implementar separadores físicos. B) Grupos familiares de 8 personas podrán compartir una mesa en salón. C) Grupos familiares de 2 personas podrán sentarse juntas en las barras. D) En las barras la distancia entre clientes solos o grupos familiares debe ser de 2 metros, de no ser posible esto, implementar separadores físicos. E) La distancia social en la barra entre el personal de atención y el cliente debe ser 2 metros, de no ser posible esto, se podrá implementar separadores físicos. F) Las zonas de alto tránsito de personal y clientes como pasillos que facilitan el desplazamiento en el salón, deben ser de al menos 2 metros entre los bordes de las mesas del salón. G) La distribución de mesas y aforo del salón debe realizarse respetando la normativa vigente sobre el distanciamiento social y el uso de equipos de protección personal, bajo responsabilidad de la empresa que brinda el servicio”. (pág. $14-15)$

Se menciona que los protocolos son más extensos y exigentes, y que esta citación es para explicar brevemente una idea de los que contiene el protocolo sanitario.

\section{Pyme y Mype en el Perú}

Las Pymes, pequeñas empresas que tienen desde 1 trabajador hasta 20 trabajadores, y Mypes, microempresas que cuentan con 10 trabajadores como máximo, son indiscutiblemente relevantes para el Perú, ya que tienen un rol decisivo en la economía, para resaltar su importancia, el presidente de la Confederación Nacional de Instituciones Empresariales Privadas, Benavides (2020) resalta a las PYMES como principal motor de la economía peruana, ya que genera trabajo a más de 7 millones de peruanos. Por lo que su relevancia es vital para el desarrollo del Perú. 
Las razones por las cuales juegan un rol importante, según el Portal Web (PQS) Para quitarse el sombrero (2020) son:

“A) Aportan al PBI aproximadamente un $40 \%$, impulsando el crecimiento económico del País; B) Ayudan a la generación de empleo, inclusión social, innovación, competitividad y lucha contra la pobreza; C) Son motor de desarrollo económico" (Portal Web)

De acuerdo con el Reporte Anual Doing Business del Banco Mundial (2019), Perú ocupo el puesto 51 de 190 economías en el pilar protección de los inversionistas minoritarios, lo que dice que nuestro pilar de avance económico son las MYPE, por lo que su avance y competitividad sostenible son fundamentales.

\section{Pyme y Mype en el Perú durante el contexto COVID- 19.}

La crisis sanitaria causada por el coronavirus, deja una crisis económica de gran escala, ya que afectó el bienestar de las empresas. Según el Portal web economía verde (2020), señala que a nivel mundial las Pymes han sido las más afectadas por esta pandemia, entre ellos los más perjudicados es el sector turismo, textil y confección. El instituto de Economía y desarrollo empresarial de la cámara del comercio de lima (2020), estima que el PBI caería 3.7\%, y que los MYPES ante este escenario son las más afectadas. En este contexto lo que MINCETUR (2020) creo con la finalidad de mantener la productividad fue el Fondo empresarial a la MYPE (FAE - MYPE).

\section{Pyme y Mype en el Perú durante el contexto COVID- 19 del sector turismo.}

Como se mencionó anteriormente, el sector turismo es uno de los sectores más golpeados por el coronavirus, a ello se le suma que el sector turismo está conformado por PYMES Y MYPES. Ante este contexto, el sector turismo está pasando una grave 
crisis. Por estas razones, hasta noviembre el ministerio de Comercio Exterior y Turismo (2020), ha creado el Fondo de Apoyo Empresarial (FAE - Turismo), el programa Reactiva Perú, el programa Turismo Emprende y Promueve Artesanía, con la finalidad de impulsar al sector turismo en el contexto COVID - 19, las cuales se explica a continuación:

$\boldsymbol{F A E}$ - Turismo. Este fondo es creado para las MYPE del sector turismo, con la finalidad de solicitar un crédito con el fin de mantener la productividad durante el estado de emergencia. Los prestamos son de hasta 750,000 según la capacidad de pago, tiene un plazo de pago de 60 meses con un periodo de gracia de hasta 18 meses. La tasa de interés será planteada de acuerdo a la entidad financiera.

Reactiva Perú. Este programa es una iniciativa aplicada por el Gobierno para contribuir a los empresarios a cumplir con sus responsabilidades económicas. El cual cuenta con 30 mil millones de soles a disposición como garantía crediticia.

Turismo Emprende. Es una iniciativa del MINCETUR para promover la reactivación económica y reconversión de micro y pequeñas empresas para impulsar el turismo y la artesanía. En el que busca la creación, desarrollo y consolidación de emprendimientos turísticos a través del financiamiento y/o cofinanciamiento de iniciativas privadas vinculadas al sector.

Promueve Artesanía. Busca apoyar la reactivación y promoción de la actividad artesanal a cargo del Mincetur en el marco de la emergencia sanitaria por COVID 19 hasta la suma de 2500000.00 soles. De esa manera impulsa la recuperación económica, espacio de promoción y comercialización de la artesanía, como también la formalización de las personas, empresas y asociaciones vinculadas a la actividad artesanal. Permitiendo generar una adecuada oferta que pueda ingresar exitosamente en los mercados locales, regionales, nacionales e internacionales. 
Hasta la fecha, se han creado está iniciativas para reactivar el sector turismo en el contexto COVID - 19, aún no hay pronóstico de que haya más iniciativas. No obstante, analizando la alarmante situación del sector turismo, estas iniciativas son necesarias para contribuir a la reactivación del turismo.

\section{Empleabilidad en el sector turístico en el Perú}

El turismo es una actividad capaz de promover empleo al mismo tiempo que su crecimiento en los destinos del país (Perú), afirma Carbajulca (2019) en su tesis de doctorado. Y eso se debe a que el Ministerio de trabajo y promoción del empleo (2013), realizó una encuesta de demanda ocupacional en el sector turismo: Restaurantes, hoteles y agencias de viaje. con el objetivo de recopilar datos de demanda ocupacional para el 2014. Y justamente en el tercer trimestre del 2013, la actividad creció en $6.1 \%$, ya que la demanda de turistas receptivos e internos era alta. Por lo que el ministerio de trabajo y promoción de empleo MTPE (2013) señala que, según las encuestas realizadas, el 47,6\% de las empresas de turismo estarían contratando nuevo personal. Hasta el 2019, la cifra de actividad turística ha incrementado, y con ello la empleabilidad. Este crecimiento se ha visto afectado por la crisis sanitaria provocada por el coronavirus.

\section{Empleabilidad en el sector turístico COVID - 19.}

Una de las principales víctimas del nuevo coronavirus es la actividad turística y su recuperación, muy probablemente, tarde más que otros sectores, señala Mariluz (2020) en el diario RPP. Canales (2020), presidente de CANATUR advierte que, para finales de diciembre del 2020, 7 de cada 10 trabajadores formales del sector turismo perderían su empleo al cierre del 2020, todo depende de la reactivación de la misma. Ya que, para finales de mayo del 2020, 400 mil trabajadores y emprendedores se quedarían sin recursos. Hasta la fecha, Parra (2020) dice que las 
empresas del sector turismo ha tenido que reducir el número de empleados y buscar subsistir más no obtener ganancias. Como también Zubieta (2020) señala que el modelo de negocio del sector turismo va a cambiar por el contexto para poder captar clientes y subsistir en el mercado, y que las nuevas tecnologías van a ser un componente importante para afrontar los retos que deja el COVID - 19.

\section{Diseño de producción de contenidos}

Producción de contenidos es una de las actividades más imprescindibles del Marketing de contenidos, ya que se entiende como la acción de generar materiales con la finalidad de informar, educar y entretener a un nicho en específico, explica Higuerey (2020). Entonces el diseño de producción de contenido es informar, educar y entretener a través de la comunicación visual, afirma Ramos (2020).

\section{Contenidos digitales para redes sociales.}

José Fermín (2017), El mundo actual gira en torno a la búsqueda de consumo de contenidos digitales. Sea en forma de texto, video o fotos, el contenido es la gran base de nuestro conocimiento y entretenimiento diario.

Videos. Según el blog inbuze digital marketing (2019), los videos son el contenido digital que mejor funciona tanto en las páginas web, como blogs o redes sociales. ya que pueden ser muy efectivos para mostrar el lado más empático y creativo de un proyecto.

Fotografías. Si bien es uno de los contenidos más utilizados, para hacer contenido digital más visual y atractivo, también mejora la experiencia de usuario. Ya que apoya textos y llama la atención de los usuarios. Según Inbuze digital marketing (2019), las publicaciones con imágenes tienen mejor cabida que una publicación de sólo texto. 
Ilustraciones. Se denomina ilustración al dibujo o imagen que adorna o documenta el texto de un libro, como también según Ane Design (2012) significa estampa, grabado o dibujo que adorna o documenta. Es un componente gráfico que realza un mensaje, Ramos (2020). Eso significa que se produce una imagen con un mensaje en particular, usando distintas técnicas de dibujo, pintura o técnicas digitales.

Infografías. Además de llevar ilustraciones, se puede entender que una infografía ayuda al lector a internet mejor a través de gráficos para que pueda interpretarse instantáneamente. El diario USA Today (1982), afirma que las infografías revolucionario el diseño, especialmente el periodístico y editorial. Dentro de los tipos de infografía están divididos en gráficos, mapas, tablas y diagramas.

\section{Estrategias de Comunicación de contenido digital}

Jorge Gijón (2020) consultor de diseño y comunicación digital dice que, las estrategias de comunicación digital es hablar de estrategias adaptadas a Internet, cuyo objetivo es definir las acciones de comunicación en Internet y elegir herramientas adecuadas para hacerlo. Por lo que una estrategia de comunicación digital es una herramienta, que forma parte del plan de marketing o plan social media de una empresa.

Para ellos se debe tener en cuenta que: A) Los objetivos deben ser globales B) Las acciones que se ejecutarán C) Instrumentos y herramientas D) El plazo para cumplir el objetivo. En general, estas estrategias darán un impulso a la imagen, marca y producto de una empresa, llegando a un público objetivo y generar crecimiento y ventas. A continuación del portal Question Pro (2020), señalan ejemplos de estrategia de comunicación digital; Marketing de contenidos, Social Media, Email Marketing, Branding, Diseño UI y UX. 


\section{Estrategias de Comunicación de contenido de redes sociales para el turismo.}

Cajal (2020) profesional de marketing especializada en empresas de turismo, ocio y restauración señala que, el marketing digital ha sido revolucionario para el sector turismo, especialmente porque se ha tenido que reciclar y adaptar a nuevos canales de comunicación en internet, por lo que aprender a conjugar el marketing digital con el marketing turístico tradicional es un reto. Por tal razón en el Tour Blog (2015) resalta que los turistas depositan toda su confianza en la red a la hora de buscar un destino, seleccionar alojamiento o un restaurante. Por lo que en un mercado tan competitivo mantenerse renovado y adaptado es vital disponer de recursos digitales para promover la comunicación. Y tener una buena estrategia de comunicación es vital para captar clientes, por lo que estar presentes en Páginas Web, Redes Sociales, Email Marketing, Inbound Marketing, etc. Es vitar para comunicarse con un cliente.

\section{Estrategias de Comunicación de contenido para redes sociales sobre el turismo}

en contexto COVID - 19. Tras la crisis sanitaria y económica que dejo el COVID 19, por lo que tener estrategias de comunicación en tiempos de crisis es recomendable para no perder contacto con los turistas, por esta razón García (2020) recomienda crear una relación emocional y generar confianza, ser claro y conciso es la clave para ser efectivo a la hora de enviar un mensaje. Informar las medidas de prevención garantiza seguridad y transparencia en tiempos de incertidumbre.

El tono de comunicación recomendado es de apoyo, tranquilidad, empatía y optimismo. Humanizar la marca demuestra solidaridad, buscar maneras creativas de comunicar eso mantiene la autenticidad. Como también ofrecer contenido con valor que responda a sus preocupaciones y dudas.

Y, por último, inspirar orgullo local por los ciudadanos y clientes, desarrollar acciones de Responsabilidad Social aporta valor agregado ya que se enfoca en las 
personas. Reportes del TurismoIn (2020) recomienda enfocar atención en el turismo interno, ya que según las estadísticas serán los primeros en reactivar el sector turismo.

\section{Estado del Arte}

\section{Misias pero viajeras.}

Misias pero viajeras es un blog de viajes, donde fomentan a la gente a viajar con un presupuesto bajo. Recomiendan hostales y restaurantes que se ajusten a un presupuesto más chico. Esta productora de contenidos se ubica en Perú, comenzó en el 2016, con el objetivo de viajar barato y enseñar a viajar de forma económica. Muchos turistas tanto internos como receptivos se interesaron en cómo viajar barato, no sólo en el Perú sino a varias partes del mundo. En estos momentos ellas sólo publican anteriores viajes, tienen un montón de suscriptores y tienen muy buen posicionamiento en redes sociales.

\section{Viaja y Prueba.}

Es un proyecto con el que recorren el norte, centro y sur del país, descubriendo sabores perdidos, rutas y rincones poco explorados de la cocina peruana. $\mathbf{i}$ El objetivo? La búsqueda de platos típicos que con los años han perdido su lugar en las mesas peruanas y hoy son reemplazados por el 'agringado' pollo broaster, la vieja y confiable milanesa frita o el clásico caldo de gallina. Este blog es peruano y fue creado en febrero del 2017. Han crecido considerablemente, y tienen muchos seguidores que se animan a ir a restaurantes de otros lugares del Perú para probar distintas sazones.

\section{Piensa en México.}

Es una campaña que Visit México está haciendo para llamar la atención de los turistas. Usan el concepto de nostalgia, para hacer extrañar a sus turistas receptivos 
los paisajes, la comida, la historia y la cultura. Utilizan el video y la poesía para hacer los videos. Esta campaña se ha realizado desde abril del 2020 para sembrar el interés del público en viajar.

\section{El bono vacanze.}

Italia lleva preparando su reactivación desde junio, y por eso el 1 Julio decidieron dar un bono para familias y parejas que quieran viajar para reactivar el turismo, esto estará vigente hasta el 31 de diciembre con toda la unión europea. Esta campaña ha sido ejecutada desde junio del 2020, con la misma finalidad de sembrar interés del público en viajar.

\section{Endless greek summer is a state of mind.}

Es una campaña que Visit GREECE está haciendo para llamar la atención de los turistas. Usan el concepto de nostalgia, para hacer extrañar a sus turistas receptivos los paisajes, la comida, la historia y la cultura. Utilizan el video y palabras inspiradoras para hacer los videos. Esta campaña se ha realizado desde junio del 2020 para sembrar el interés del público en viajar. 


\section{Capítulo IV}

\section{Público Objetivo}

\section{Turistas receptivos de 50 a 60 años.}

Las siguientes características son de reportes y estadísticas de vacacionistas extranjeros, hechos por Promperú (2020), a continuación:

Características. Los turistas receptivos de 50 a 60 años significan el 25\% de la población de turistas que viene al Perú, sus principales motivos para venir son: Recreación y ocio. Por lo general su estadía dura entre 8 a 10 días, el gasto por viaje es aproximadamente de 104 dólares por día.

Viaje Familiar. La estadía dura de 15 a más días, el gasto es menor en comparación a los otros tipos de viaje, gastan alrededor de 42 dólares al día.

Viaje por negocios. La estadía no pasa de 5 días a 6 días, no obstante, el gasto es mayor, gastan 141 dólares por día.

"En su mayoría de los viajeros de 50 a 60 años son hombres, el 60\% de ellos vienen de países latinoamericanos, anglosajón y Europa. Los turistas de Oceanía, África y Europa son quienes más gastan al visitar el Perú, lo que significa que generan mayores ingresos al sector. Es público objetivo, normalmente suele planear sus viajes en agencias de viaje por internet" (pág. 2-5)

En los últimos reportes del perfil de vacacionista receptivo de Promperú (2019), los lugares que más visitaron fueron Puno y Arequipa. Para el 2018 fueron Lima y Cusco. Las redes sociales más usadas en general son Facebook, le sigue Instagram y por último Twitter y LinkedIn. Las agencias de viaje que alguna vez usaron para viajar fueron: Booking, Tripadvisor, Airbnb y luego Expedia. En el mismo reporte indica que las actividades más realizadas son de cultura, por ejemplo, actividades de cultura urbana como pasear por la ciudad y visitar museos. Su nivel socioeconómico es de $\mathrm{A} / \mathrm{B}$, les gusta hacer Turismo de cultura, naturaleza y aventura. Según las 
estadísticas del 2018 de PROMPERU (2020), las actividades más realizadas fueron:

turismo de cultura y diversión, le sigue turismo de naturaleza y aventura. Por otra parte, según Bloom consulting, casi el $60 \%$ de ellos tienen miedos a viajar es más grande que el deseo de hacerlo ya que se rehúsan a viajar por salud.

\section{Concepto}

El concepto es: Seguridad para viajar con libertad.

Frase utilizada para expresar el concepto clave para la comunicación del proyecto. La principal finalidad es cumplir con las necesidades y expectativas del público objetivo. Por esta razón, la frase conceptual denota confianza. El cambio de comportamiento en el Turista, cambio el perfil del turista como también el valor del turismo, por ejemplo, la idea que se tiene de hacer turismo peruano en este nuevo contexto COVID - 19.

\section{Moodboard.}

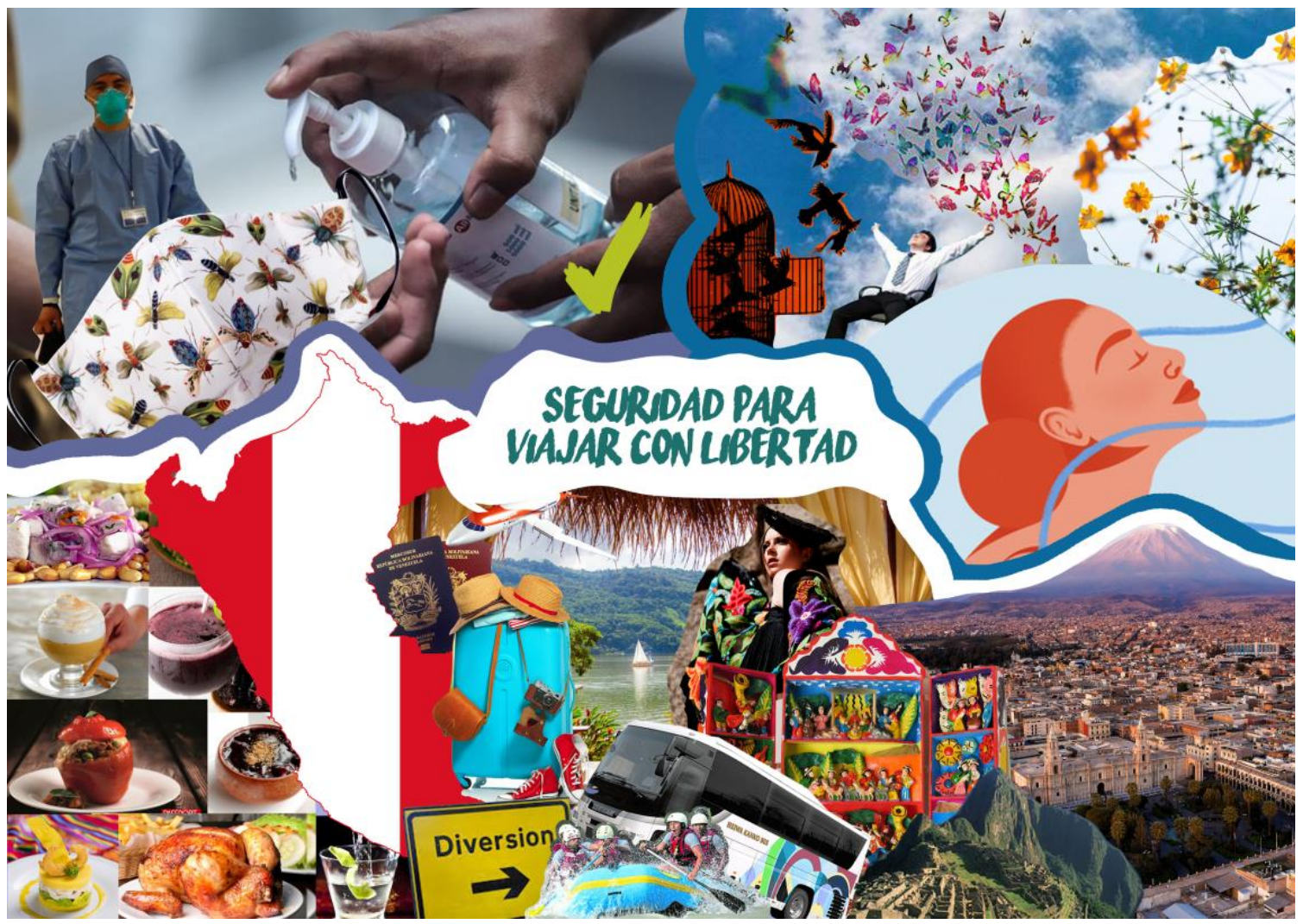

Figura 1: Moodboard del concepto "Seguridad para viajar con libertad", Katia Ramos (2020) 
Este Moodboard es una compilación de imágenes referenciales de las palabras:

"Seguridad, viajar y libertad", las imágenes escogidas reflejan cada palabra, para así combinarlas y entender de forma global en concepto. Teniendo en claro que significa cada palabra a través de imágenes, se puede determinar los colores que mejor representan el concepto, la línea gráfica y el tono a seguir.

\section{Paletas de color.}

\section{Colores principales.}

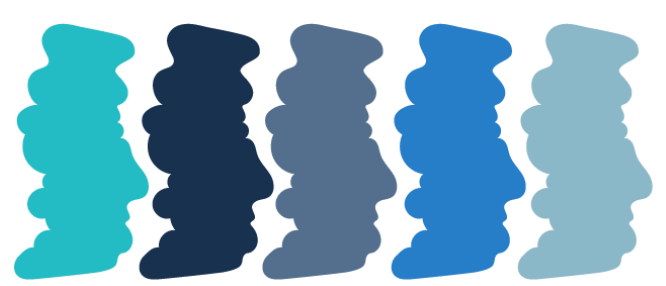

Figura 2. Colores principales para creación del logo "Seguridad para viajar con libertad", Katia Ramos (2020)

\section{Colores secundarios.}

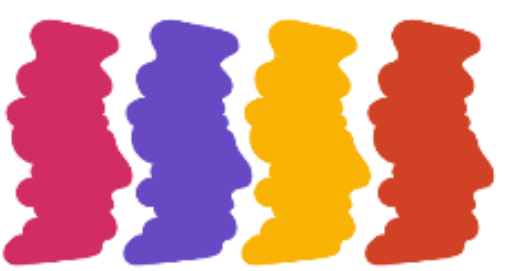

Figura 3. Colores secundarios, opcionales para el concepto "Seguridad para viajar con libertad", Katia Ramos (2020)

Está paleta de colores está inspirada en la confianza y la libertad, uso los azules como colores principales ya que la seguridad es el mensaje principal de la comunicación. Según la psicología de color los azules representan seguridad, confiabilidad y tranquilidad. Por otro lado, para complementar la seguridad con la diversión y libertad, están colores cálidos como el rosado, el naranja, amarillo y purpura, con la finalidad de trasmitir alegría, aventura y diversión. Usando estos colores, se busca el equilibrio entre diversión y seguridad. 


\section{Tipografías.}

XPLOR BOLD

ABCDEFGHI JKLMNOP QRSTU VWXYZ

0123456789
MONTSERAT

Family font

ABCDEFGHI JKLMNOQR STUVWXYZ abcdefghijkl mnñopqrst

uvwxyz

\section{9}

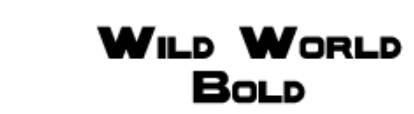
ABCDEF대| JKLMNOPQRST UVWXYZ

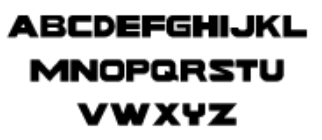

\section{$01 z=4=578$}

Figura 4. Tipografías para el concepto "Seguridad para viajar con libertad", Katia Ramos (2020) Las tipografías escogidas fueron Xplor Bold, Wild World Bold y Montserat Family. Con estas tipografías capto la esencia de viajar la cual está entre aventura y libertad, lo que es fundamental para comunicar bien que es una marca de diseño de producción de contenido de TURISMO. Montserat Family Font, es específicamente para comunicar mensaje con un tono más serio, específicamente esta tipografía será usada los mensajes de seguridad.

\section{Metodología del Diseño}

El proyecto consiste de hacer una campaña de diseño de contenidos para redes sociales, con el objetivo de promover la idea de viajar al Perú de manera segura en el contexto COVID - 19, para lograr está comunicación, la campaña tiene cuatro fases, que son las siguiente:

\section{Primera Fase.}

Creación de Redes Sociales. Estas redes sociales serán Facebook, Instagram y YouTube. El usuario es: @makana.viajar tanto para Facebook como para Instagram. Esto es necesario para que la marca pueda ser etiquetada fácilmente en ambas redes. 
Por otra parte, Makana tendrá su propia cuenta de Gmail, la cual es:

makana.viajar@gmail.com, para que sea una cuenta independiente.

Publicidad en Redes Sociales sobre los objetivos de la campaña. Se diseña cuatro posts Social Media, explicando cuales son los objetivos de la campaña de Makana, el cual se llama ¿Y si viajamos? Estos objetivos son los siguientes:

Objetivo 1. Animar al turista receptivo a viajar al Perú (Safe Travel)

Objetivo 2. Brindar información de calidad acerca del turismo, que les brinde más confianza de viajar al Perú.

Objetivo 3. Informar y publicitar cuales son los lineamientos que exige el Promperú en todos los establecimientos.

Objetivo 4. Recomendar Pymes que estén cumpliendo esos lineamientos, la información será proporcionada por iPerú.

Objetivo 5. Contribuir con el aumento del flujo de turistas receptivos.

Estos objetivos serán publicados la primera semana de la campaña, usando post publicitarios en Facebook e Instagram.

\section{Segunda Fase.}

Publicidad en Redes Sociales la nueva manera de viajar durante el COVID - 19. En esta segunda fase del proyecto, el objetivo será informar y publicitar los protocolos de prevención que exige MINCETUR, para que la gente tenga conocimiento de las medidas de prevención que todo establecimiento debe tener, por ejemplo, recomendar un kit de viaje efectivo para la nueva forma de viajar en este contexto COVID - 19. Está información será dividida tres semanas.

Primera Semana. 5 post publicitarios de los protocolos sanitarios de hoteles categorizados, según mincetur. 
Segunda Semana. 5 post publicitarios de los protocolos sanitarios de restaurantes, según mincetur.

Tercera Semana. 5 post publicitarios de los protocolos sanitarios de Agencias de Turismo, según mincetur.

Cuarta Semana. 3 post publicitarios de protocolos de sanitarios de transporte según mincetur y video publicitario del Kit de Seguridad para viajar con Libertad.

\section{Tercera Fase.}

Publicidad en Redes Sociales de puntos turísticos por región.

Tabla 2

Puntos turísticos por Región

\begin{tabular}{|l|l|l|}
\hline Costa & Sierra & Selva \\
\hline Ica & Arequipa & Tarapoto \\
\hline Paracas & Cusco & Moyobamba \\
\hline
\end{tabular}

Los puntos turísticos a publicitar se dividen por región: Costa, Sierra y Selva. (Katia Ramos, 2020)

Como se puede observar en la tabla 2, son dos puntos turísticos por región, para esta segunda fase, el diseño de contenido se basa en fotografías tomadas por Katia Ramos antes de la pandemia, estás fotografías irán acompañadas de el logo o el isologo de la campaña junto a una frase inspiradora o poética en español e inglés, tales como: Viaja seguro, Libera tus alas, Respira Tranquilo, Nuevas experiencias, Nuevos Horizontes, Camino a la aventura, etc. Por otra parte, los posts serán publicados de la siguiente manera:

Primera Semana. Se hablará de Ica, donde se diseñarán post publicitarios de puntos turísticos de Ica, y por otra parte hoteles y restaurantes recomendados por TurismoIn. Esto también incluye video publicitario. 
Segunda Semana. Se hablará de Paracas, donde se diseñarán 5 post publicitarios mostrando la belleza de Paracas, y por otra parte hoteles y restaurantes recomendados por TurismoIn. Esto también incluye video publicitario. Tercera Semana. Se hablará de Arequipa, donde se diseñarán 5 post publicitarios mostrando la belleza de Arequipa, y por otra parte hoteles y restaurantes recomendados por TurismoIn. Esto también incluye video publicitario. Cuarta Semana. Se hablará de Cusco, donde se diseñarán 5 post publicitarios mostrando la belleza de Cusco, y por otra parte hoteles y restaurantes recomendados por TurismoIn. Esto también incluye video publicitario.

Quinta Semana. Se hablará de Tarapoto, donde se diseñarán 5 post publicitarios mostrando la belleza de Tarapoto, y por otra parte hoteles y restaurantes recomendados por TurismoIn. Esto también incluye video publicitario. Sexta Semana. Se hablará de Moyobamba, donde se diseñarán 5 post publicitarios mostrando la belleza de Moyobamba, y por otra parte hoteles y restaurantes recomendados por TurismoIn. Esto también incluye video publicitario.

\section{Cuarta Fase.}

Video informativo del Mágico Parque de las Aguas. El parque de las aguas es uno de los lugares a los cuales se puede ir durante esta cuarentena. Están abiertos porque MINCETUR ha comprobado que está cumpliendo todos los lineamientos que exigen. Para explicar eso de manera eficiente se dividirá en escenas.

Primera escena. Armar el Kit de seguridad de Makana / Safe Kit From Makana.

Primera escena. Mostrar las medidas que se toman en el parque de las aguas. Tercera escena. Mostrar el ambiente, buenas tomas de fotografía y video. Cuarta escena. En caso hayan autorizado el vender comida, ver si están utilizando las medidas adecuadas. 
Quinta escena. Antes de subir al auto, mostrar todas las medidas que debemos tomar, como desinfectar nuestros sacos y zapatillas. Como también sugerir que en caso vengan en este contexto alquilen un automóvil. (Ver si hay uno que cumpla con las reglas)

Sexta escena. Al llegar a casa, sugerir poner a lavar su ropa y bañarse automáticamente. Tras ello dar un feedback.

Detalles. Todo será hablado en castellano, pero tendrá que haber subtítulos en inglés ya que al público al que nos dirigimos son turistas receptivos. El video debe ser animado.

\section{Relación entre Problema, Público Objetivo y Proyecto}

Problema. Pronóstico de Reducción de flujo en turistas receptivos de 50 a 60 años a raíz de el alto número de contagios y muertes por COVID - 19 en el Perú.

Público Objetivo. Turistas receptivos de 50 a 60 años.

Proyecto. Diseño de Contenido para Redes Sociales de Turismo Peruano.

La relación de estos tres factores es basa en contribuir a la crisis que el sector turismo está enfrentando en el contexto COVID - 19, enfocándose en convencer al público de 50 a 60 años de viajar al Perú. La principal razón por la cual la campaña "¿Y si viajamos? / What If? we travel de Makana se dirige este P.O es porque representa el 25\% del flujo de turistas que llegan al Perú, y como consecuencia del COVID - 19, este target siente más desconfianza al viajar en comparación a las generaciones más jóvenes. Lo que es terrible, ya que son un segmento que genera buenos ingresos al Perú, ya que prefieren los viajes de buena calidad.

Para recuperar la confianza de este target se debe trabajar con publicidad a través de las redes sociales, con la finalidad de informarlos, convencerlos y emocionarlos de viajar al Perú. 


\section{Marca del Proyecto}

\section{Naming.}

Makana viene de Maskana lo que significa explorador o búsqueda en quechua cuzqueño, le quite las "s" porque ya existían otras marcas que se llamaban igual en las redes sociales.

\section{Tipo de logo.}

Makana es una marca que busca ser versátil, estacional y flexible como el turismo, por lo que su logo es un Logotipo que se convierte en Imagotipo, ya que el objetivo es que sea reconocido por la tipografía y su línea gráfica. Por otro lado, la imagen y/o logo del imagotipo cambia constantemente por el tipo de campaña en la que se encuentre Makana, por ejemplo, la campaña ¿Y si viajamos? Esta campaña añade un descriptor y una imagen que lo caracterice, en este caso, el escudo.

Logotipo. Makana está compuesta por la tipografía Xplor Bold, con un fondo que sigue la línea gráfica de la tipografía.

Imagotipo. Este logo se compone gráficamente de una imagen como de palabras, sin que estás se encuentren agrupadas bajo un mismo dibujo. Dentro de las características de este imagotipo es que es desacoplable, es decir, puede separarse en dos partes (ícono y palabras), con la finalidad de que aún separadas puedan ser identificable.

Imagen y/o logo. El logo o imagen que acompaña a la tipografía, en el caso de Makana, es un escudo, el cual refleja seguridad.

Descriptor. El texto utilizado para la campaña “Y si viajamos" es Wild World Bold, el cual acompaña al logotipo en la parte inferior.

Colores. Makana en sí no tiene un color determinado ya que cambia por campañas, pero en definitiva el Blanco es un color que siempre se utilizará en la tipografía. Por 
otra parte, durante la campaña ¿Y si viajamos? los colores principales serán los azules, complementados por colores cálidos como los amarillos y naranjas.

\section{Makana.}

La marca Makana es una productora de contenidos de Turismo, el cual tiene diseña campañas para contribuir a aumentar el flujo de turistas en todo el mundo. En este caso, con la campaña de ¿Y si viajamos? / What if - we travel? Apunta a contribuir a la reactivación del turismo peruano.

\section{Cultura Makana.}

Versatilidad, Empático, Estacional y Aventurero.

\section{Resultado.}
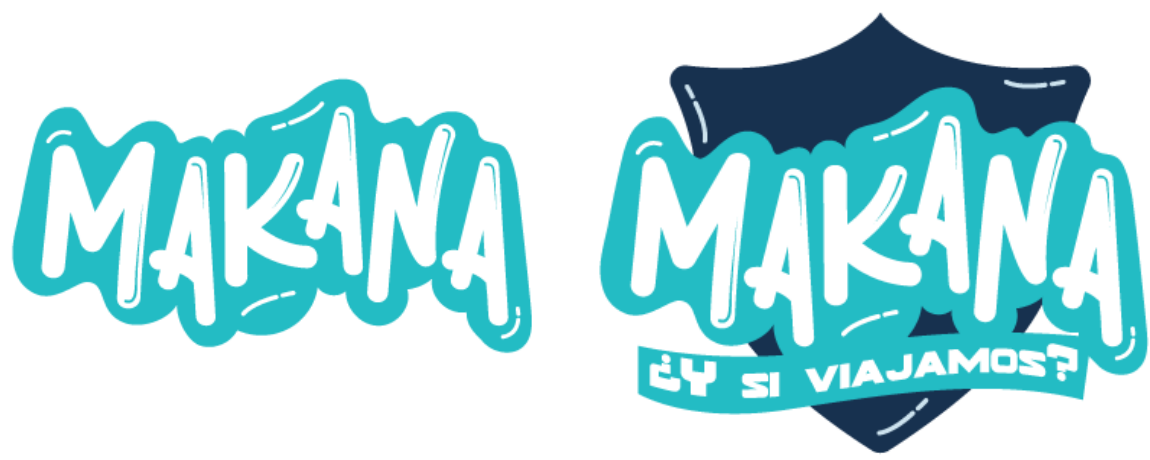

Figura 5. Logo de Makana, Katia Ramos (2020)

\section{Diseño de la Comunicación}

La comunicación de este proyecto busca ser empática, versátil y busca compartir una dualidad entre seguridad y aventura. En los post y videos publicitario el tono de la comunicación sería semiformal para denotar esa dualidad que se busca a la hora en la que un turista receptivo de 50 a 60 años busca hacer un viaje en el contexto COVID - 19. Para que entienda el mensaje se entienda correctamente se usa colores y tipografías adecuadas para cada mensaje, por ejemplo, para post publicitarios de seguridad y protocolos los colores serán azules y la tipografía Montserrat, ya que 
guarda un tomo formal, por el otro lado para post publicitarios de puntos turísticos los colores serán cálidos y usando tipografías como World Wild Bold y Xplor Bold, los cuales connota aventura y diversión. El contenido de este proyecto se adecua a las necesidad y dudas de este público objetivo, junto a los gustos y preferencias, dentro las cuales están fotografías de exterior, ilustraciones, infografías y videos. Es seguro que el mensaje será entendido ya que el proyecto responde a una necesidad constante y el diseño está creado para atraerlos visualmente, lo que en conjunto con la estrategia de comunicación fortifican la comunicación de la campaña en general. Una manera de asegurar que el mensaje perdure en el tiempo es la constancia con la que se haga los posts publicitarios, crear horarios y descriptores que acostumbren al público objetivo a consumir los posts, en pocas palabras, la única manera de hacer que el mensaje perdure en el tiempo es posicionarse constantemente, usando el mismo tono, concepto, valores y palabras clave para hablar con el P.O. Los canales que se usarán para estar constantemente en comunicación con la persona Byer son Redes Sociales como: Facebook, Instagram, YouTube, Tiktok, Página Web y Blog. Por esta razón, la campaña tiene 4 fases: Presentación, Seguridad, Puntos Turísticos y por último Videoblogs. Los cuales, en conjunto, pueden repetirse cada vez que se hable un punto turístico del Perú.

\section{Piezas Empleadas}




\section{FАCЕВООК.}

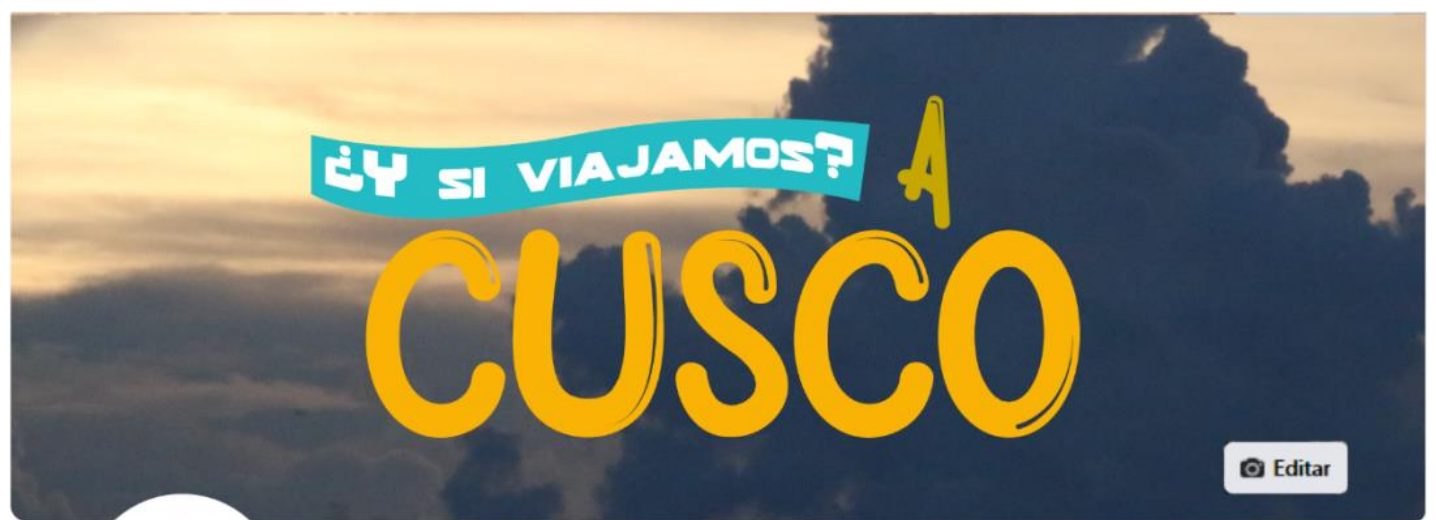

Makana

@Makana.viajar.Creador digital

+ Agregar un botón

\begin{tabular}{|c|c|c|c|c|c|c|}
\hline Inicio & Grupos & Más - & $\mp$ Promocionar & $\odot$ Ver como visitante & Q & $\cdots$ \\
\hline
\end{tabular}

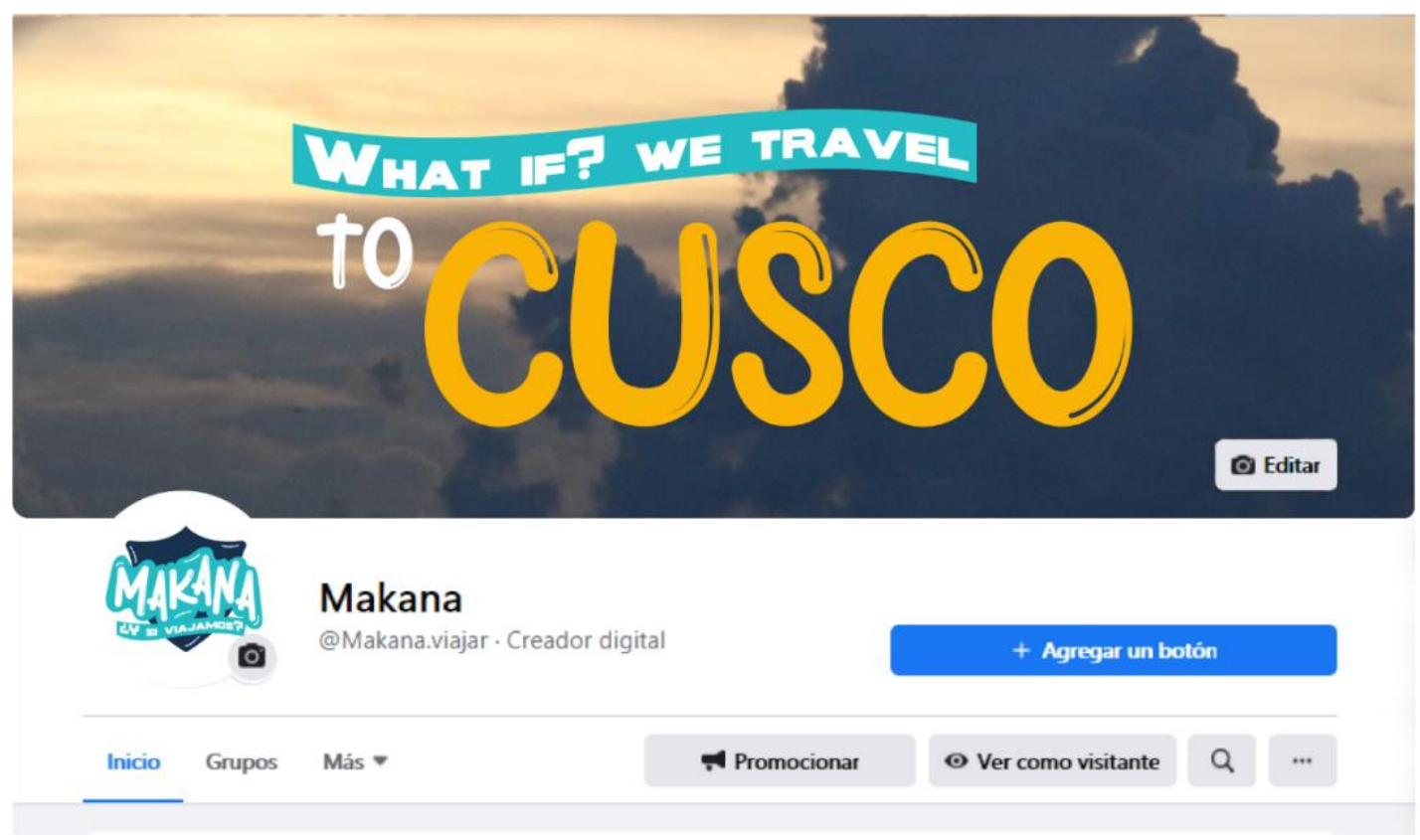



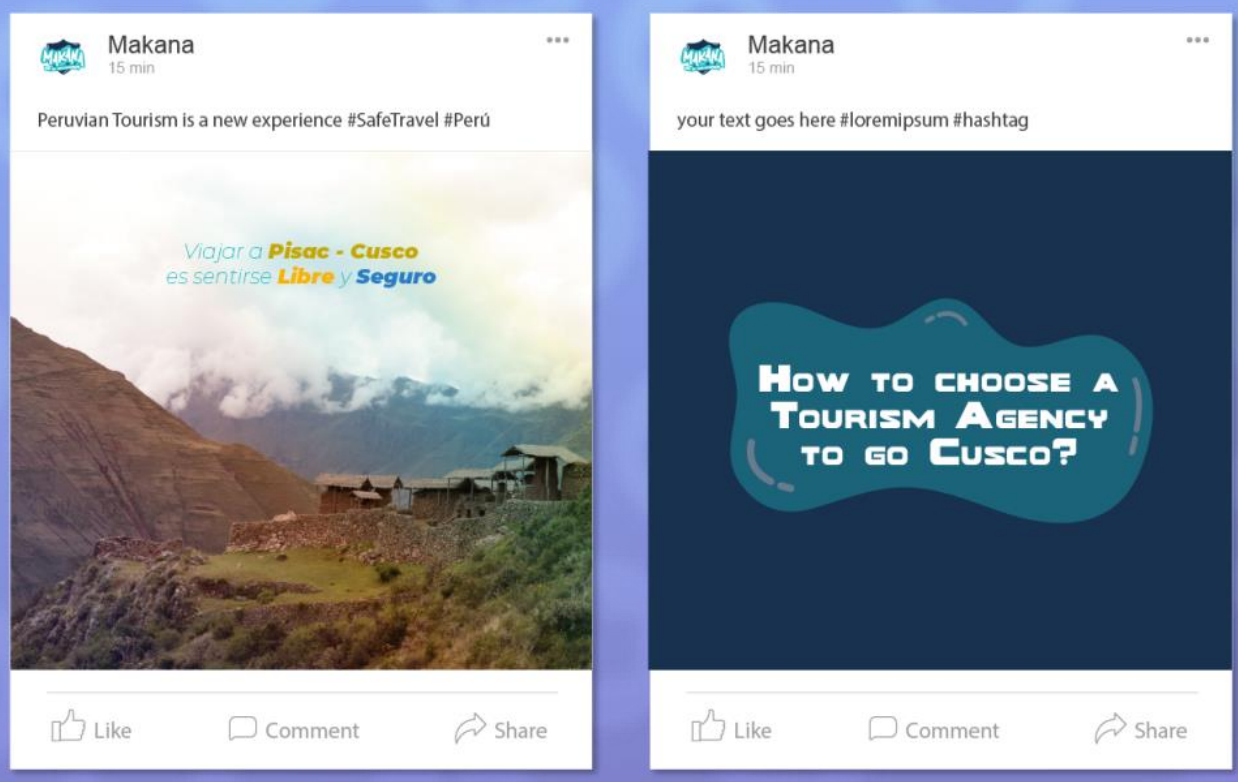

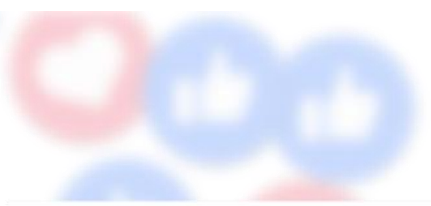

Makana

your text goes here \#loremipsum \#hashtag

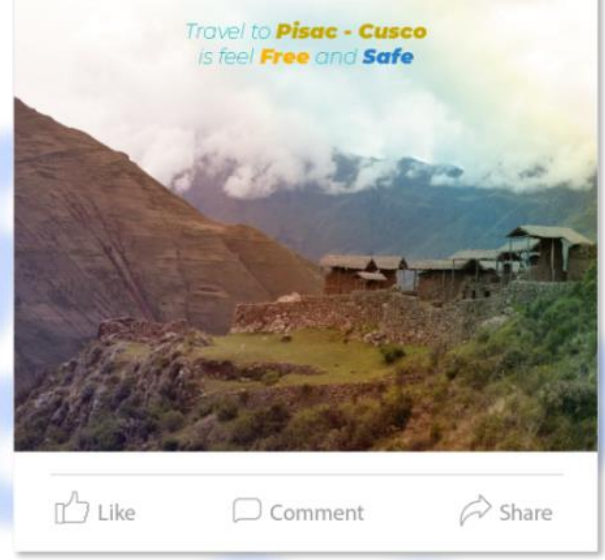

\section{(2) user_name}

your text goes here \#loremipsum \#hashtag

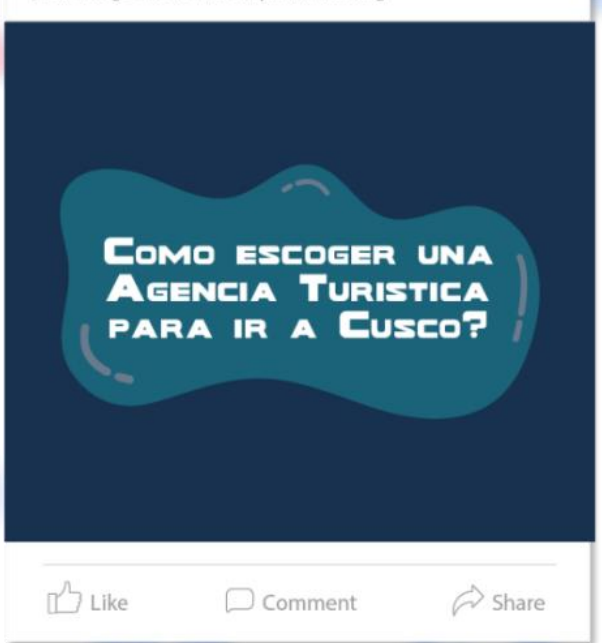


YOUTUBE.
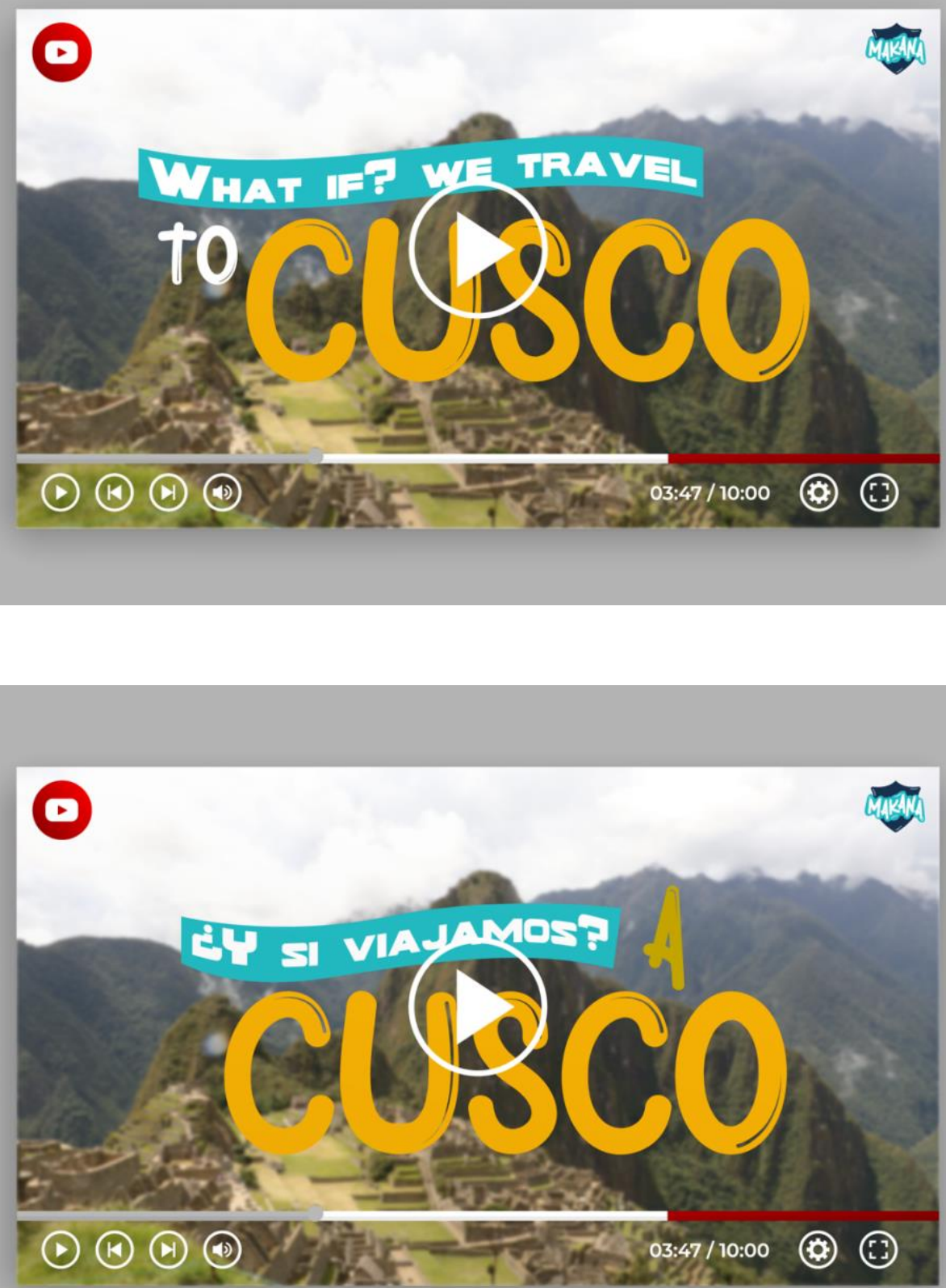
INSTAGRAM

Instagram

a Search

内 $\nabla$ (2)

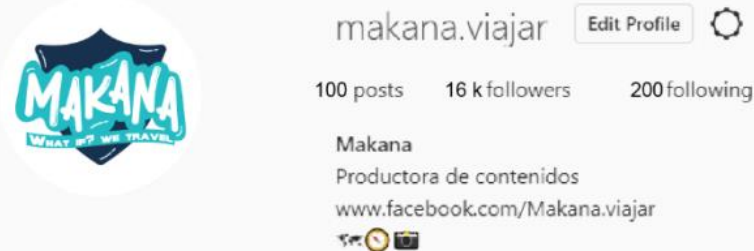

囲 POST

๑ IGTV

त SAVED

目 TAGGED
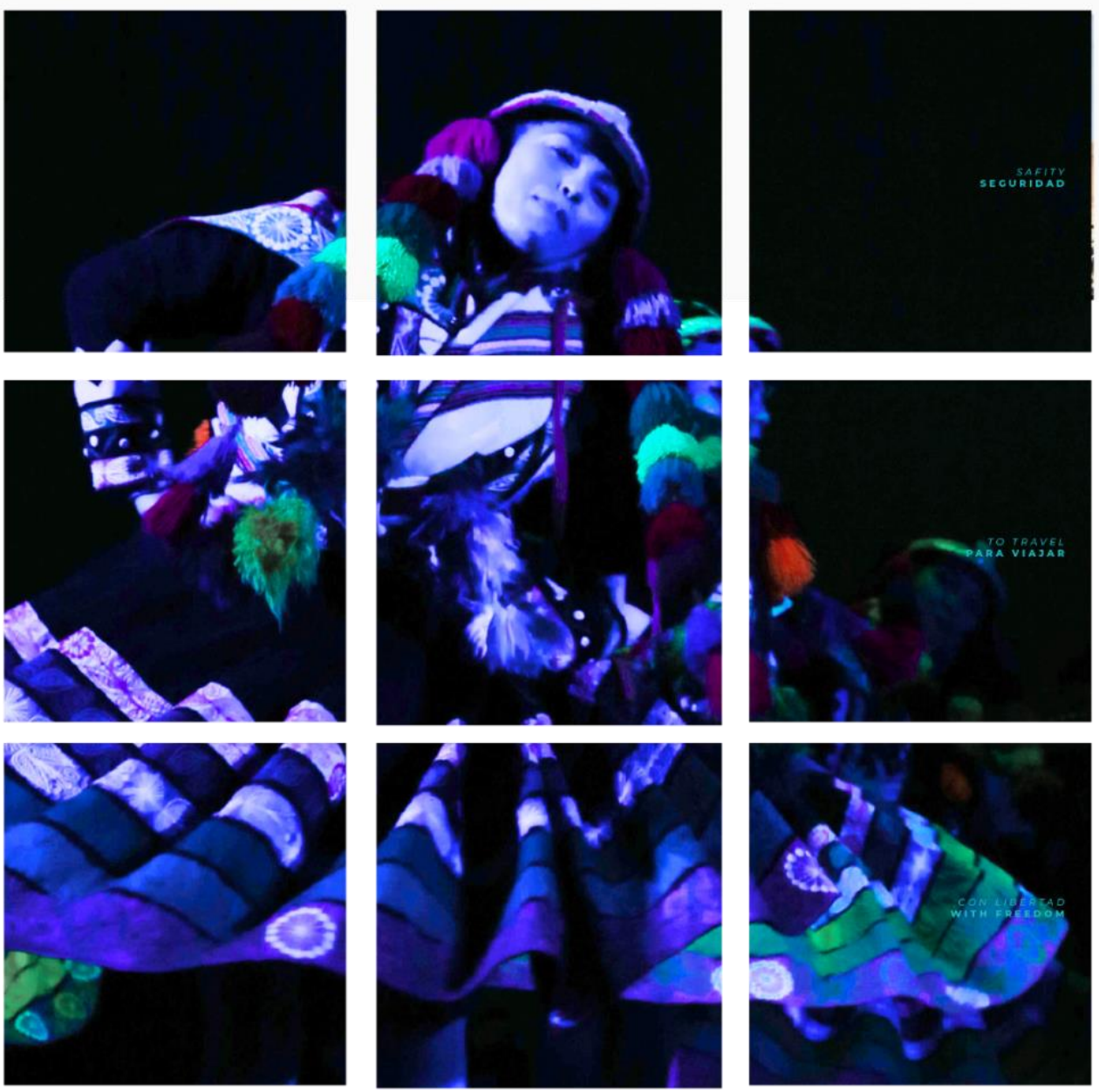

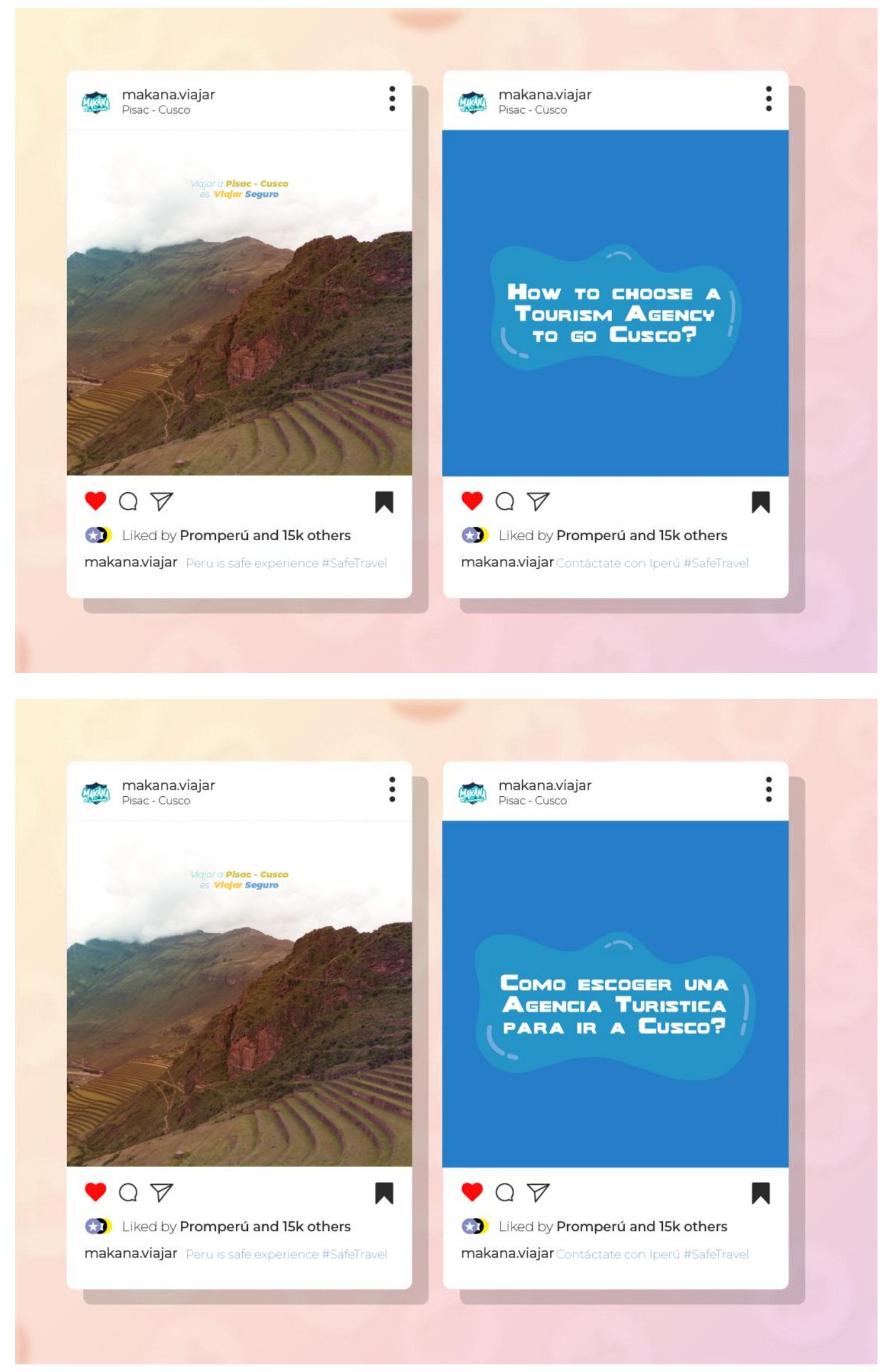


\section{Reflexiones}

Desde finales de agosto del 2020, cuando el índice de contagio era altísimo en el Perú, el problema que atravesaba el Turismo era más que evidente y las apreciaciones de expertos del turismo a los que entrevisté manifestaron que este problema era muy preocupante para el sector y su crecimiento, las encuestas que realizadas a profesionales del sector que estaban desempleados y turistas internos de 50 a 60 años tampoco eran favorables, esto se debe que ante el miedo de contraer el virus y la débil infraestructura de salud en el Perú. Durante la investigación y estudio de campo en redes sociales y páginas web, el contexto mejoró a partir de noviembre del 2020, ya que durante a inicios de noviembre el turismo retomo sus actividades gracias que la infraestructura de salud estaba en mejores condiciones y la vacuna para el coronavirus existe y tiene fecha de llegada al Perú. Además, que el turismo peruano para conseguir la confianza del turista receptivo obtuvo el sello Safe Travels, este sello contribuye al problema de desconfianza de los turistas internos como receptivo. De todos modos, el pronóstico de que el 2021 será un año difícil para el Turismo aún persiste, por eso he creado la campaña de diseño de contenidos de redes sociales para el turismo peruano "¿Y si viajamos? / What if - we Travel?” bajo la marca Makana, una productora de contenidos de redes sociales para el turismo. Con el objetivo que informar y convencer al turista de 50 a 60 años de viajar al Perú con la finalidad de contribuir a la reactivación económica del turismo. Como Diseñadora Gráfica, este proyecto puede convertirse en un emprendimiento, lo que suma bastante a mi trayecto y perspectiva ya que un proyecto social le añade más valor a mi especialización. 


\section{Conclusiones}

\section{Conclusiones (150-200 palabras)}

Desde la perspectiva de los jueces de pares concluyen que el proyecto es viable y que aporta tanto de forma social y comercial, como también demuestra que una buena investigación y proyecto la comunicación visual puede aportar mucho a la sociedad. Si es factible aplicarlo, ya que el tema de la desconfianza es un tema que debe ser trabajado y toma bastante tiempo, es todo un desafío. Este proyecto si funcionaría con bastante trabajo y un presupuesto adecuado, ya que está bien el proyecto y la investigación están bien engarzadas.

Desde la evaluación de los jueces de pares, no ha habido comentario acerca de si se puede ampliar, pero desde la perspectiva de quien realiza el proyecto, podría ampliarse a sectores como exportaciones y transporte. Este proyecto es aplicable a actores más jóvenes como millenialls y generación x. Según Alejandra de la Cruz (2020) se puede volver un emprendimiento rentable. El proyecto requiere de crear contenido constantemente y para ser sostenible es bueno que trabaje por campañas. Todo depende del contenido creado y las campañas creadas por temporadas. 
Anexos

\section{Tablas}

Tabla 1

Perfil del Turista Extranjero 2018

\begin{tabular}{|l|l|l|l|l|l|l|}
\hline $\begin{array}{l}\text { Tipo de } \\
\text { Turista }\end{array}$ & Año & $\%$ & $\begin{array}{l}\mathrm{N}^{\circ} \mathrm{de} \\
\text { vuelos }\end{array}$ & $\begin{array}{l}\text { Gasto por } \\
\text { persona }\end{array}$ & Noches & Hotel / Hostal \\
\hline Centennial & $1995-2016$ & $18 \%$ & 478534 & $\begin{array}{l}955 \\
\text { dólares }\end{array}$ & 13 noches & $\begin{array}{l}1 \text { a 2 estrellas } \\
\text { Hotel /Hostal }\end{array}$ \\
\hline Millenial & $1979-1994$ & $47 \%$ & 1295272 & $\begin{array}{l}971 \\
\text { dólares }\end{array}$ & 11 noches & $\begin{array}{l}\text { 3 estrellas } \\
\text { Hotel / Hostal }\end{array}$ \\
\hline $\begin{array}{l}\text { Generación X } \\
1965-1978\end{array}$ & $18 \%$ & 504294 & $\begin{array}{l}964 \\
\text { dólares }\end{array}$ & 8 noches & $\begin{array}{l}\text { o 2 estrellas } \\
\text { Hotel / Hostal }\end{array}$ \\
\hline $\begin{array}{l}\text { Baby Boomer } \\
\text { Silenciosa }\end{array}$ & $1946-1964$ & $16 \%$ & 427486 & $\begin{array}{l}1177 \\
\text { dólares }\end{array}$ & 8 noches & $\begin{array}{l}3 \text { estrellas } \\
\text { Hotel / Hostal }\end{array}$ \\
\hline
\end{tabular}

Tabla 2

Puntos turísticos por Región

\begin{tabular}{|l|l|l|}
\hline Costa & Sierra & Selva \\
\hline Ica & Arequipa & Tarapoto \\
\hline Paracas & Cusco & Moyobamba \\
\hline
\end{tabular}




\section{Figuras}

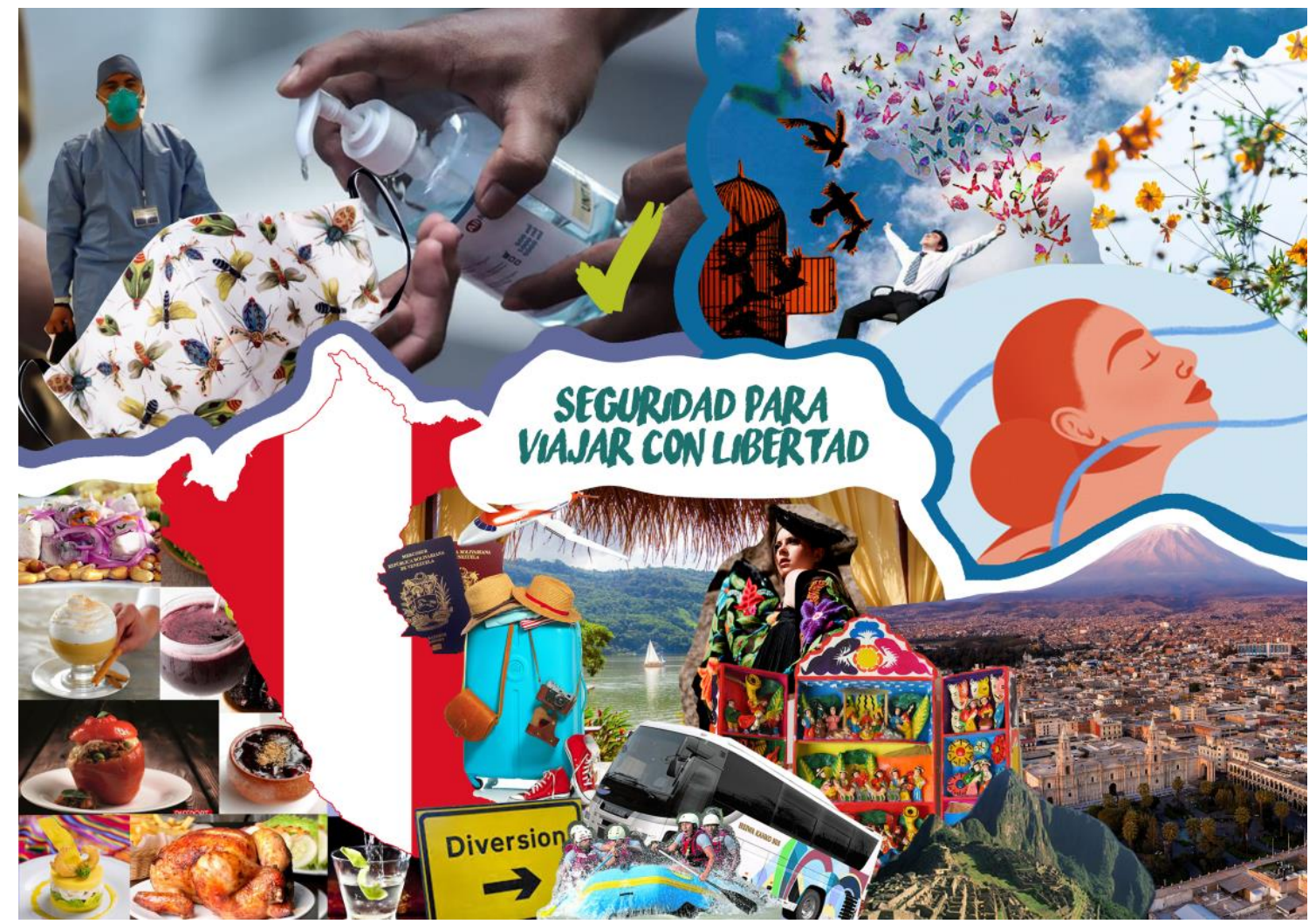

Figura 1: Moodboard del concepto "Seguridad para viajar con libertad", Katia Ramos (2020)

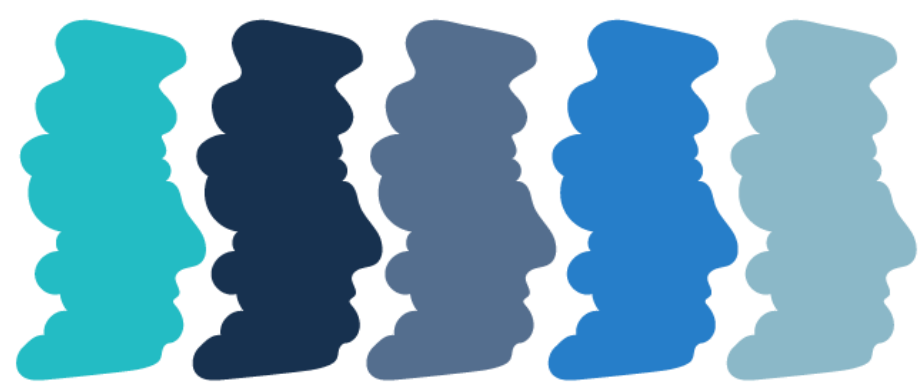

Figura 2. Colores principales para creación del logo "Seguridad para viajar con libertad", Katia Ramos (2020)

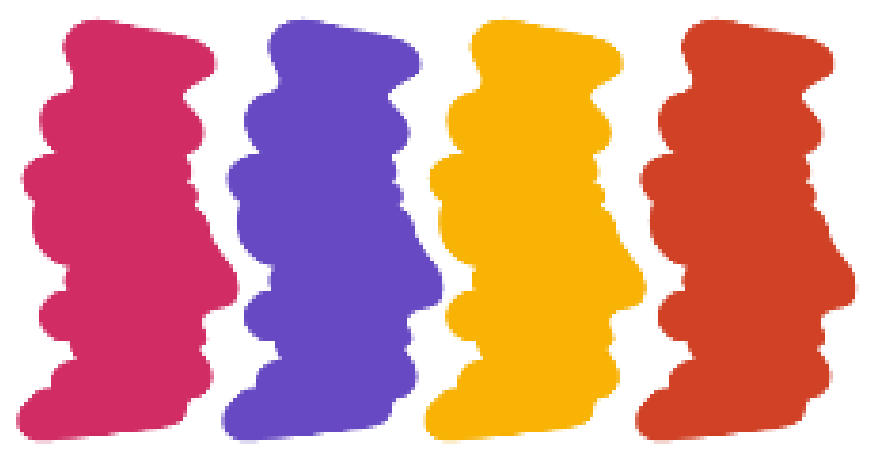

Figura 3. Colores secundarios, opcionales para el concepto "Seguridad para viajar con libertad", Katia Ramos (2020) 
XPLOR BOLD
Family font

ABCDEFGHI JKLMNOP QRSTU VWXYZ

0123456789

\section{ABCDEFGHI JKLMNOQR STUVWXYZ abcdefghijkl mnñopqrst uvwxyz}

\section{9}

\section{WILd WORLd}

BOLD

\section{ABCDEFGHI JKLMNOPGRST UVWXYZ}

\author{
ABCDEFEHIJKL \\ MNOPGRSTU \\ VWXYz
}

\section{1ze45-789}

Figura 4. Tipografías para el concepto "Seguridad para viajar con libertad”, Katia Ramos (2020)
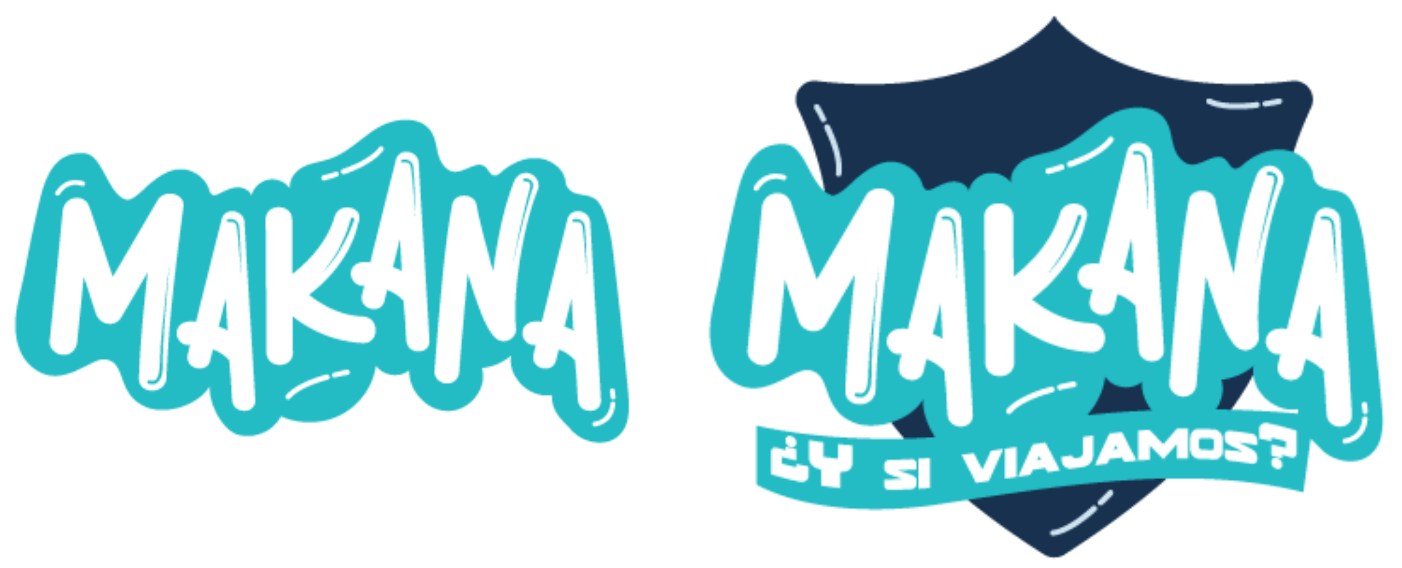

Figura 5. Logo de Makana, Katia Ramos (2020)

\section{Entrevistas}

Expertos del Sector Turismo.

Sandra Zubieta - directora de la Carrera de Administración Hotelera, Turismo,

Gastronomía y Arte Culinario. Las siguientes preguntas fueron:

Primera pregunta. ¿Cuánto Tiempo llevas siendo directora de la carrera HTG?

Empecé como profesora por 5 años, luego asumí la coordinación de Administración hotelera y en el año 2017 asumí la dirección de la Facultad. 
Segunda pregunta. En este contexto COVID - 19 ¿Cuáles son los principales desafíos que enfrenta el sector turístico / sector hotelero? Es un hecho que el COVID ha golpeado de manera muy significativa a nuestro sector, impactando directamente en las posiciones de trabajo, se han perdido muchísimas dentro de este lapso de este tiempo. Sabemos que el turismo es la tercera fuente ingresos de divisas de nuestro País. La perspectiva ahora es muy crítica, porque la mayor parte de ingresos se generan por el turismo internacional, y los aeropuertos están cerrados. Hasta que no haya una vacuna, vamos a seguir en una crisis turística, de por si algunos hoteles intentan abrirse mercado con segmento nacional para subsistir, mas no para ganar lo que hacían antes. Las razones de porque es que el turismo nacional siente temor, el presupuesto es más limitado, la crisis es general, eso ha obligado a bajar las tarifas. Como por ejemplo el westin, el cual tiene una tarifa muy baja. Mi perspectiva de lo que va a pasar en unos meses, todavía veo un sector hotelero, turístico y gastronómico golpeado que va a tratar de subsistir. Vamos a tratar de hacer todo para mantenernos más no generar ingresos, pero si por lo menos se puede cubrir gastos operativos igual en restaurantes que están abiertos, pero no están facturando lo que hacían 9 meses atrás, queda reinventarse, ver nuevas opciones, delivery en restaurantes, en ciudades tratar de captar ese negocio para hospedar a gente que están trabajando en las mineras. Tengo conocidos que están trabajando con este público, pero también tiene sus retos ya que se pueden enfermar por COVID - 19. Sin aerolíneas, sin movimientos el sector turismo está paralizado, los guías turísticos están en un punto más crítico, hay algunos que se han reinventado, que están haciendo cursos virtuales, pero es para mantenerse.

Tercera pregunta. Durante el tiempo y la historia del turismo ¿Este sector ha enfrentado una crisis igual o peor a esta? ¿Hay alguna que se le asemeje? Esta es la 
crisis más intensa no tiene comparación. Cuando recién inicie la carrera, Perú recién salía del terrorismo y la colera, era un país que tenía una imagen muy dañada a nivel internacional, sin infraestructura. Yo me fui del país, volví después de 6 años a Perú, y vi una transformación importante, había una infraestructura hotelera mucho más acorde para las nuevas exigencias del mercado, se había mejorado la conectividad, había más autopistas, en general Perú tenía una mejor imagen ante el mundo. Y se empezaba a posicionar con el tema de la gastronomía. Sin embargo, en el año 2001 me toco vivir la crisis del 11 de septiembre, en ese momento fue una de las más duras, y pensamos que era lo peor que habíamos visto. Como te digo, yo sabía que en los 70'con el terrorismo en sí, era muy difícil que hubiera trabajo para el sector turismo, agencias, no lo viví directamente, cuando comencé a estudiar se escuchaba, se observaba pocas opciones laborales, mal pagado. En el año 2001, yo estaba trabajando en un hotel y pasa esto, pues fue caótico, una gestión de crisis terrible, porque las personas no pudieron salir porque los aeropuertos se cerraron, los que llegaron no podían ingresar, hubo unos días en las que podían irse todos, pero no venían porque la gente suspendía sus vuelos y eso duro ocho meses a un año en la que la gente comenzó a tomar confianza. Como tú lo dijiste, en esa época las aereolíneas comenzó a bajar sus tarifas de forma muy sustancial, porque la gente no viaja y debían motivarlos a hacerlo, igual esta pasando ahora, yo intenté hacer una reservación para diciembre y conseguí pasajes muy accesibles, pagando ahorita y con flexibilidad, además, algo que no encontrarías así nomás. Pero es de alguna manera una medida para poder recuperar todo este tiempo que han estado paralizados, si bien es cierto que el 2001 que pensamos era lo peor que podía pasar, paralizo un tiempo el sector nos logramos recuperar rápido. Esta crisis si ha sido mucho mayor, porque esto no es un atentado terrorista de 1 en 100, esto es algo que está pasando en todo el 
mundo ye es una pandemia que acaba con la vida de las personas, y efectivamente la gente está con mucho miedo y nuestro sector se vio demasiado afectado. Y si le sumamos como país, las condiciones sanitarias son muy pobres realmente, complica mucho la situación, en verdad es terrible. Me recuerda a los de la colera, ya que la gente no venía porque pensaba que se podía contagiar y cuando llegaron tomaban agua en botella porque tenía mucha desconfianza. Igual ahora, viene aquí con todo lo que se ve en las noticias, es una realidad si un turista va a Machupichu y le pasa algo a donde recurre, tiene que encontrarse esas opciones buena para el turismo en cuanto a clínicas y hospitales de un nivel apropiado para dar esta tranquilidad y confianza para el viajero.

Cuarta pregunta. Como profesionales del tema ¿Cuál es su perspectiva personal en todo este asunto?

Sí, es una realidad que los microempresarios son los que están demasiado golpeados, porque las empresas con respaldo financiera como cadenas de hoteles, cadenas de restaurantes que simplemente están viendo cómo se reinventan y lo están haciendo. Pero para un restaurante pequeñito, una agencia de viajes, un guía turístico definitivamente tiene que recurrir a una inversión mayor y tienen que adaptar toda su operación a los nuevos protocolos, que me parecen son los correctos, las inversiones en la APP de todos los equipos que van a utilizar, eso es caro es costoso. Entonces han estado sin ingresos por meses, y ahora no poder operar porque tienen que realizar otra inversión y usar dinero que no tienen, porque muchos de ellos al inicio han asumido la planilla de su gente porque se pensaba que duraría 2 semanas, 3 semanas y después cuando ya no pudieron más recurrieron a la suspensión perfecta, ósea están endeudados y tienen que invertir más todavía, es algo que si requiere del apoyo del gobierno, vemos otros casos otro países donde se han usado fondos del gobierno para 
apoyar a estos microempresarios. En otros países como Italia por ejemplo les han dado un bono a las personas para poder viajar, para motivarlos a viajar y es lo que se requiere también aquí. La gente no lo hace porque está sin dinero como lo mencioné la gente esta con temor, puede haber un segmento que podría animarse a hacerlo. También se que aquí están ese poyo como reactiva Perú o el FAE turismo, lo cual dan un incentivo a las microempresas para poder reactivar sus negocios y salir adelante. Pero nuevamente ellos lo pueden hacer, pero si la gente no se motiva a viajar, van a estar listos para recibir viajeros, pero van a tener viajeros, ¿Cómo funciona eso? Ahí lo que hizo Italia fue bueno, tengo familia en Italia y ellos empezaron a viajar y ayudar a las pequeñas empresas reactivar sus negocios. Aunque es otra realidad, pero si considera el apoyo del gobierno primordial y las campañas de Promperú a motivar al viajero nacional. Es lo que se tiene que hacer, y ya se ha hecho en otros momentos cuando hemos tenido estas crisis temporales en cusco durante las inundaciones. E hicieron una campaña llamada cusco pone, y la gente se animó a viajar, hay un segmento que podrá hacerlo con todos lo protocolos, y es momento de apoyar, es mi apreciación, el que puede apoyar a nuestro sector.

Quinta pregunta. ¿Y exactamente cuál sería ese turista ideal? Por ejemplo, gente mayor de 50 no está muy interesada en viajar porque está dentro de la población vulnerable y eso les da miedo.

Se hizo un estudio den Turismo In, donde ellos estudiaron el perfil de este nuevo viajero e indicaron que eran los millenialls, según ese estudio son los Millenial porque temen menos al virus porque eran menos sensibles, supuestamente. Supuestamente, porque este virus es imprescindible, ya que todos se contagian. Pero los Millenial que mantienen el empleo y tienen esas condiciones económicas para poder viajar, tienen mayor facilidad a una movilización practica y cómoda en 
comparación las personas de 50 años, quienes buscan más comunidad y esta más sensible al contagio, y bueno yo me iría por ese segmento, aunque hay de todo, hay gente mayor de 40 años que va a hoteles sólo para relajarse. El tema aquí es que la cantidad de ambientes sanitarios que tenemos, por ejemplo, ya se están encontrando más camas en UCI, entonces eso da tranquilidad por que el indica de contagio está disminuyendo, lo que mejora a nuestro país.

Sexta pregunta. He visto que están haciendo webinar en la Usil dirigido a estudiantes de la facultad HTG ¿Cuáles son las principales razones para dar esas charlas?

Hay varias razones, estamos en una situación difícil, de aislamiento para los jóvenes es difícil porque nunca han pasado una crisis, yo he vivido el terrorismo de chica, y era una realidad

Séptima pregunta. ¿Cómo este sector debe adaptarse a este contexto o post contexto? ¿Qué tendrían que hacer las pequeñas y medianas empresas para ganarse la confianza de sus clientes?

Diana Guerra - directora de la Carrera de Administración Hotelera, Turismo, Gastronomía y Arte Culinario, hasta Julio del 2020.

Primera pregunta. ¿Cuánto Tiempo llevas siendo directora de la carrera HTG? Segunda pregunta. En este contexto COVID - 19 ¿Cuáles son los principales desafíos que enfrenta el sector turístico / sector hotelero?

Tercera pregunta. Durante el tiempo y la historia del turismo ¿Este sector ha enfrentado una crisis igual o peor a esta? ¿Hay alguna que se le asemeje? Cuarta pregunta. Como profesionales del tema ¿Cuál es su perspectiva personal en todo este asunto? 
Quinta pregunta. He visto que están haciendo webinar en la Usil dirigido a estudiantes de la facultad HTG ¿Cuáles son las principales razones para dar esas charlas?

Sexta pregunta. ¿Cómo este sector debe adaptarse a este contexto o post contexto? ¿Qué tendrían que hacer las pequeñas y medianas empresas para ganarse la confianza de sus clientes?

\section{Juez de Pares}


Lima 23 de abril 2020

Seńores,

Carrera de Arte y Diseńo Empresarial

Facultad de Humanidades

Universidad San lgnacio de Loyola

Por medio de la presente me dirijo a ustedes a fin de poder dar una opinión objetiva respecto al proyecto Diseńo de contenidos para redes sociales de Turismo peruano para contribuir a aumentar el flujo de turistas receptivos de 50 a 60 ańos en el Perú diseńado por el Bachiller Katia Luisa Ramos Diaz referido al pronóstico de reducción del flujo de turistas de 50 a 60 ańos para el 2021

Por lo tanto, al analizar y revisar el proyecto minuciosamente encuentro que el mismo es importante para el sector turismo dar a conocer de manera digital la nueva manera de viajar e incentivar a las personas especialmente al segmento de 50 a 60 ańos ya que ellos buscan una fuente de información que le de seguridad al tomar la decisión de viajar. Mostrando un diseńo llamativo, las personas podrán visitar y conocer más de las páginas por medio de anuncios en Facebook y YouTube, redes más usadas por esa generación.

Atentamente,

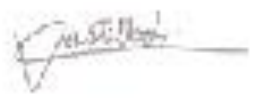

Bachiller Vanesa Castillo Layseca 


\author{
Señores, \\ Carrera de Arte y Diseño Empresarial \\ Facultad de Humanidades \\ Universidad San Ignacio de Loyola
}

Por medio de la presente me dirijo a ustedes a fin de poder dar una opinión objetiva respecto al proyecto Diseño de contenidos para redes sociales de Turismo peruano para contribuir a aumentar el flujo de turistas receptivos de 50 a 60 años en el Perú diseñado por el Bachiller Katia Luisa Ramos Diaz referido al pronóstico de reducción del flujo de turistas de 50 a 60 años para el 2021.

Por lo tanto, al analizar y revisar el proyecto minuciosamente encuentro que el mismo es interesante y representa todo un desafío. Al estar dirigido al segmento entre 50 a 60 años, el cual es uno de los más vulnerables en el tema del contagio, es importante que se cree contenido para que se puedan sentir seguros al momento de viajar. Por otro lado, el hecho de que hoy en día haya más acceso a internet y redes sociales, se puede llegar a más personas y adaptando el contenido de acuerdo al público al que uno se dirige.

Atentamente,

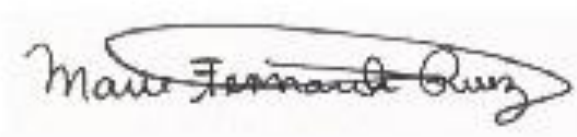

Bachiller Maria Fernanda Ruiz 
Señores,

Carrera de Arte y Diseño Empresarial

Facultad de Humanidades

Universidad San Ignacio de Loyola

Por medio de la presente me dirijo a ustedes a fin de poder dar una opinión objetiva respecto al proyecto Diseño de contenidos para redes sociales de Turismo peruano para contribuir a aumentar el flujo de turistas receptivos de $\mathbf{5 0}$ a $\mathbf{6 0}$ años en el Perú diseñado por el Bachiller Katia Luisa Ramos Diaz referido al pronóstico de reducción del flujo de turistas de 50 a 60 años para el 2021.

Por lo tanto, al analizar y revisar el proyecto minuciosamente encuentro que la investigación y el planteamiento del mismo tienen una coherencia y relación muy bien engarzadas, destacando su propuesta de comunicación, convirtiéndolo en un trabajo cuyo desarrollo demuestra el poder de la investigación y la comunicación visual para resolver problemas comerciales y sociales.

Atentamente,

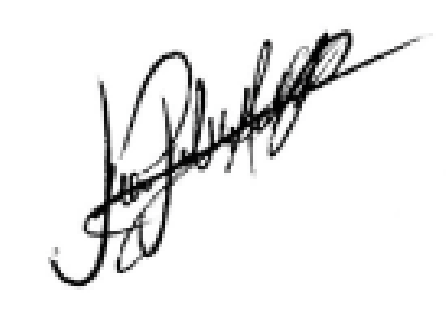

Mg. Juan Pablo Miguel Aponte Ruidias 
Señores,

Carrera de Arte y Diseño Empresarial

Facultad de Humanidades

Universidad San Ignacio de Loyola

Por medio de la presente me dirijo a ustedes a fin de poder dar una opinión objetiva respecto al proyecto Diseño de contenidos para redes sociales de Turismo peruano para contribuir a aumentar el flujo de turistas receptivos de 50 a $\mathbf{6 0}$ años en el Perú diseñado por el Bachiller Katia Luisa Ramos Diaz referido al pronóstico de reducción del flujo de turistas de 50 a 60 años para el 2021.

Por lo tanto, al analizar y revisar el proyecto minuciosamente encuentro que el mismo es VIABLE

Atentamente,

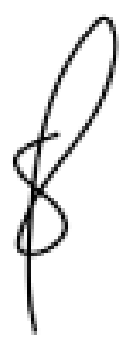

$\overline{\text { Bachiller Alejandra de la Cruz }}$ 
Señores,

Carrera de Arte y Diseño Empresarial

Facultad de Humanidades

Universidad San Ignacio de Loyola

Por medio de la presente me dirijo a ustedes a fin de poder dar una opinión objetiva respecto al proyecto Diseño de contenidos para redes sociales de Turismo peruano para contribuir a aumentar el flujo de turistas receptivos de $\mathbf{5 0}$ a $\mathbf{6 0}$ años en el Perú diseñado por la Bachiller Katia Luisa Ramos Diaz referido al pronóstico de reducción del flujo de turistas de 50 a 60 años para el 2021.

Por lo tanto, al analizar y revisar el proyecto minuciosamente encuentro que el mismo es un trabajo bien desarrollado, pero se necesita reforzar los conceptos sobre turismo y además al ser una tesis el cual tiene un aporte académico a la sociedad se necesitan mayores fuentes que refuercen las ideas expuestas en la tesis.

Atentamente,

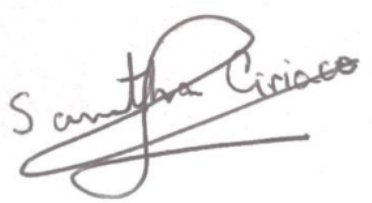

Licenciada Samantha Ciriaco 


\section{Referencias Bibliográficas}

World Tourism Organization (2020), UNWTO Briefing Note - Tourism and COVID 19, Issue 1 - How are countries supporting Tourism recovery?, UNWTO, DO.

Angela Me 2020 How Covid is changing the world: a statistical perspective Book Committee for the Coordination of Statistical Activities

McKinsey 2020 A global view of how consumer behavior is changing amid COVID 19 Article

Bloom Consulting and D2 Analytics 2020 COVID - 19 The Impact on tourist Behaviours Reporte

Promperú, Turismo in 2020 Intención de viaje por cuarentena ¿Cuánto tiempo tomará el peruano en volver viajar? Reporte

Nick De May, Philippe De Ridder 2020 Shifts in the Low Touch Economy Reporte Maximiliano E Korstanje 2020 El turismo en un mundo incierto: desafíos para el siglo xxi en un contexto post covid 19 Ensayo Teórico

Barcachán, Fratelli, Rojas, Tafur 2017 Planeamiento Estratégico para la industria peruana de Turismo Tesis

Jaime Briceño 2020 Programa Comercial Express de la Ruta de la Competitividad Turística Reporte

OMT 2020 Recuperación del Turismo después del COVID - 19 Reporte.

Vásquez, Torres, Butler, Canales, Stoessel, Koechlin, Canseco 2020 / Webinar USIL Reinventando El Turismo En Tiempos de COVID - 19 - WEBINAR Diana Guerra, 2020 / Universitat de Girona Planificación estratégica del turismo cultural en clave de COVID- 19 - Conversatorio / Webinar Raúl Garcia, Mayo 2020 \& Promperú El futuro del turismo, recomendaciones para empresarios del sector. 
Promperu (Agosto, 2020) Intención de viaje poscurentena

Bloom consulting (Junio, 2020) Covid - 19, El impacto sobre comportamiento Turístico Rivero y Rozas, Promperú (2020) Análisis del turismo interno y percepción del entorno pos - covid 19

Jiménez y Jiménez (2013) Ecoe Ediciones Turismo: tendencias globales y planificación estratégica

Barómetro OMT del Turismo Mundial, mayo 2020 Con especial enfoque en el impacto de la COVID - 19

Organización Mundial del Turismo (2016) Alianza entre turismo y cultura en el Perú Modelos de colaboración entre turismo, cultura y comunidad Ayuntamiento de Elche y Organización mundial de turismo (2015) 1 congreso internacional patrimonio religioso y turismo: tipos, tendencias y desafíos - Elche España Promperú, Turismo in 2020 Agosto Intención de viaje Post cuarentena file:///C:/Users/Usuario/AppData/Local/Temp/Rar\$DIa 98416.10375/Presentacion_ Perspectivas Turismo Interno.pdf Barchet, Bhargava, Catena 2020 April A global view of how consumer behavior is changing amid COVID - 19 https://www.mckinsey.com/business-functions/marketingand-sales/our-insights/a-global-view-of-how-consumer-behavior-is-changing-amid$\underline{\text { covid-19 }}$

Bloom consulting and D2 - Analytics 2020 COVID - 19, the impact on tourist behaviours

file://C:/Users/Usuario/AppData/Local/Temp/Rar\$DIa97620.4498/COVID\%20Impact \%20on\%20tourist\%20behaviours.pdf Available at bloom-consulting.com/journa Promperu, and turismo in 2019 Perfil del Turista extranjero file:///E:/LICENCIATURA/Uploads_perfiles_extranjeros_42_PTE_2019_PUBLICACI 
ON.pdf

Rivero y Rozas 2020 Análisis del turismo interno y percepción del entorno pos - covid 19 www.promperu.gob.pe/TurismoIN/covid-19

Angela Me, Haishan Fu 2020 How Covid is changing the world: a statistical perspective Committee for the Coordination of Statistical Activities

MINSA 2020 Sala Situacional COVID - 19 Perú

https://covid19.minsa.gob.pe/sala_situacional.asp

Google noticias 2020 Coronavirus (COVID - 19)

https://news.google.com/covid19/map?hl=es-

419\&mid=\%2Fm\%2F02j71\&gl=US\&ceid=US\%3Aes-419

MEF 2020 Donaciones COVID - 19

https://www.datosabiertos.gob.pe/dataset/donaciones-covid-19-ministerio-deeconom $\% \mathrm{C} 3 \% \mathrm{ADa}-\mathrm{y}-$ finanzas-mef

INEI 2020 Agosto Situación del mercado laboral en lima metropolitana http://m.inei.gob.pe/biblioteca-virtual/boletines/informe-de-empleo/1/\#lista CANATUR 2020 Canatur: siete de cada 10 trabajadores del turismo perderán su empleo al cierre del 2020 https://portaldeturismo.pe/noticia/canatur-siete-de-cada-10trabajadores-del-turismo-perderan-su-empleo-al-cierre-del-2020/ El economista 2020 Abril En peligro, 100 millones de empleos en el sector turístico por contingencia de covid - 19 : WTTC https://www.eleconomista.com.mx/empresas/Enpeligro-100-millones-de-empleos-en-el-sector-turistico-por-contingencia-de-Covid-19$\underline{\text { WTTC-20200426-0011.html }}$

OMT 2020 Barómetro OMT del Turismo mundial 2020, Con especial enfoque en el impacto de la COVID - 19 https://www.eunwto.org/doi/epdf/10.18111/9789284421954 
OMT, CEGOS Y OIT 2020 Enero El futuro del trabajo en el turismo y el desarrollo de las competencias https://www.e-unwto.org/doi/epdf/10.18111/9789284421404 UNMTO 2018 Tourism Employment https://www.unwto.org/tourism-employment INEI 2020 mayo Demografía empresarial en el Perú http://m.inei.gob.pe/bibliotecavirtual/boletines/demografia-empresarial-8237/1/\#lista ATV noticias 2020 Más de 50 mil empresas del sector turismo han cerrado https://www.youtube.com/watch?v=Y1KHE54NK6I OMT 2020 World Tourism Barometer https://www.promperu.gob.pe/TurismoIN/covid$\underline{19}$ ?Tipo $=27$ 